Estudios Constitucionales, Año 12, No 1, 2014, pp. 15-70.

ISSN 07180195

Centro de Estudios Constitucionales de Chile Universidad de Talca

"La violencia contra las mujeres en las producciones de la comisión y la Corte Interamericana de Derechos Humanos"

Laura Clérico y Celeste Novelli

\title{
LA VIOLENCIA CONTRA LAS MUJERES EN LAS PRODUCCIONES DE LA COMISIÓN Y LA CORTE INTERAMERICANA DE DERECHOS HUMANOS*
}

\author{
VIOLENCE AGAINST WOMEN IN THE PRODUCTION OF THE INTER-AMERICAN \\ Comission and the Inter-American Court of Human Rights
}

\author{
LAURA ClérICO** \\ Universidad de Buenos Aires - Argentina \\ lauraclerico@yahoo.com \\ Celeste Novelli*** \\ Universidad de Buenos Aires - Argentina \\ celestenovelli@gmail.com
}

RESUMEN: El trabajo identifica y analiza los estándares que surgen de las producciones de la CIDH $y$ de la Corte IDH respecto de: la definición de violencia contra las mujeres/de género; la calificación de los actos $u$ omisiones que implican violaciones a los derechos humanos y como expresión de la desigualdad de poder; las obligaciones estatales y medidas reparatorias para erradicar la violencia de género. El análisis identifica avances en la incorporación de la perspectiva de género en las producciones del SIDH; sin embargo, asimismo devela que aún es restringida la concepción de violencia contra las mujeres aplicada por la Corte IDH al estar aún muy centrada en la violencia sexual y no ampliarse a otros aspectos; también alerta que el énfasis puesto en la medida reparatoria de acceso a la justicia opaca pensar en otras acciones adecuadas para la erradicación de la violencia contra las mujeres.

ABSTRACT: This article aims to identify and analyze the legal standards built by the Inter-American Commission and Inter-American Court of Human Rights on the following topics: the definition of violence against women/gender violence; the legal description of the actions or omissions that constitute a breach to human rights and which are also an expression of gender inequality; obligations and appropriate means of reparations owed by States to eradicate gender violence.

The analysis finds progress on gender mainstreaming in the productions of the Inter American System of Human Rights, but also a narrow conception of violence against women focused mainly on sexual

\footnotetext{
* Trabajo recibido el 16 de abril de 2013 y aprobado el 19 de marzo de 2014.

** Abogada (UBA), LLM y Doctora en Derecho (Kiel). Profesora de Derecho Constitucional (UBA). Investigadora del CONICET. Agradecemos a Leticia Vita y a Federico De Fazio la lectura crítica y los comentarios sobre el trabajo.

*** Becaria CIN, Facultad de Derecho de la Universidad de Buenos Aires.
} 
violence. This approach leaves out many other important aspects. Furthermore, this paper warns about the emphasis on access to justice as a reparatory measure that difficult to consider the implementation of other adequate actions towards the eradication of violence against women.

PALABRAS CLAVE: Violencia contra las mujeres, Sistema Interamericano de Derechos Humanos, Corte Interamericana, Comisión Interamericana, Acceso a la justicia.

KEY WORDS: Violence against women, Inter American System of Human Rights, Inter American Court, Inter American Commission, Access to Justice.

\section{EL SIDH y LA VIOLENCIA CONTRA LAS MUJERES}

El desarrollo de estándares sobre violencia de género en el Sistema Interamericano de Derechos Humanos (en adelante, SIDH) puede ser periodizado ${ }^{1}$ y caracterizado según se trate del accionar de la Comisión Interamericana de Derechos Humanos (en adelante, CIDH), en comparación con el de la Corte Interamericana de Derechos Humanos (en adelante, Corte IDH). El criterio de clasificación sería el activismo de los órganos en el desarrollo de las producciones sobre violencia de género. Si 1994 es el año que en forma simbólica es tomado expresamente por la CIDH para dar por iniciada la etapa de compromiso activo de su accionar en pos de la erradicación de la violencia de género; para la Corte IDH sería el año 2009 cuando expresamente en la sentencia de Campo Algodonero examina una situación estructural de violencia contra mujeres. ${ }^{2}$ El accionar de la CIDH contrasta así con el papel "extremadamente modesto" desempeñado por la Corte IDH, ${ }^{3}$ por lo menos, hasta el año 2006.

Sin embargo, el accionar activista de la CIDH no se condice con su reticencia en la remisión de demandas individuales referidas a cuestiones de género a la Corte

\footnotetext{
1 Estos desarrollos deben ser leídos en un contexto ampliado, es decir, más allá del SIDH. Al respecto, Lemaitre señala que en especial la "violencia contra las mujeres" como denuncia surge merced al trabajo de los movimientos feministas durante los noventa, $y$, en particular, del feminismo radical y al feminismo latinoamericano. El feminismo radical sostiene que el lugar de subordinación de las mujeres "no corresponde principalmente a su exclusión del poder ni a los efectos de la discriminación, sino a su dominación por diversos medios violentos", Lemaitre (2008); Sierra Camargo (2012), p. 86.

2 La Corte IDH y la CIDH parecen utilizar indistintamente los conceptos de "violencia hacia la mujer" y "violencia de género" a pesar de que tienen significados distintos. La fórmula de la "Violencia contra la mujer" visibiliza a la víctima, pero no a quien es el sistemático victimario ni cuáles son los ámbitos y vínculos habituales de la violencia; el término "Violencia doméstica" ilumina sólo el ámbito de la violencia, mientras que la frase "Violencia familiar" se concentra en el vínculo, pero no en las relaciones de poder existentes al interior de la estructura familiar. La denominación como "Violencia de género" da cuenta de "las estructuras simbólicas que justifican y naturalizan la violencia" y, finalmente, la expresión "violencia sexista" hace eje "en las relaciones de poder entre los sexos y el sistemático disciplinamiento de un sexo sobre otro" (MAfría 2012).

3 Tramontana (2011), p. 142; Medina Quiroga (2003), pp. 907-930.
} 
IDH. Hasta el año 2002 habría remitido sólo un caso entre todos los trabajados, los otros finalizaron en la Comisión como resultado de una solución amistosa o con la publicación de un informe final. Esto tuvo consecuencias múltiples. En lo inmediato, se le privó a la víctima la compensación que podría haber recibido de haber ganado el caso. Pero más allá de esto, la reticencia a remitir los casos a la Corte imposibilitó consolidar una jurisprudencia sobre los derechos de las mujeres, en especial, en casos de violencia de género. Esto no deja de ser curioso, ya que la Comisión que parecía haber mostrado mayor compromiso, por lo menos hasta el 2006 imposibilitó, con su reticencia, que las cuestiones de género tuvieran visibilidad en el SIDH. No se le puede escapar a la Comisión que las sentencias de la Corte IDH tienen mayor visibilidad en el continente que los pronunciamientos de la Comisión. Recién a partir de 2006 la Corte IDH dictó sentencia en seis casos sobre violencia de género. Sin embargo, en defensa de la Comisión, se podría argumentar que la Corte IDH bien pudo haber desarrollado la perspectiva de género en otros casos anteriores al 2006 aun cuando la CIDH no le hubiera presentado los casos como violaciones a los derechos de las mujeres. Piénsese, entre otros, en los casos Caballero Delgado y Santana c. Colombia, sobre detención de dos personas (entre ellas una mujer) por una patrulla militar y su posterior desaparición; ${ }^{4}$ Loayza Tamayo c. Perú, sobre detención arbitraria de una mujer5; o Maritza Urrutia c. Guatemala, sobre el secuestro y la detención arbitraria de una militante durante el conflicto guatemalteco. ${ }^{6}$

Asimismo, no deberíamos perder de vista el papel desempeñado por las ONG dedicadas a la protección de derechos humanos y que nutren (en algunos casos, monopolizan ${ }^{7}$ ) las denuncias que llegan al SIDH. Varias ONG que se dedican al litigio internacional no incluían hasta el 2001 en sus respectivas agendas acciones

\footnotetext{
4 Corte IDH, Caballero Delgado y Santana c. Colombia (1995), Sentencia de 8 de diciembre de 1995, párrs. 36, 38-39. La Corte IDH no tomó como relevante de los hechos probados que sólo la mujer detenida hubiese sido amarrada y desnudada por los militares, y puesta a caminar en ese estado por la región.

5 Corte IDH, Loayza Tamayo c. Perú (1997), Sentencia de 17 de septiembre de 1997.

6 Corte IDH, Maritza Urrutia c. Guatemala (2003), Sentencia de 27 de noviembre de 2003.

7 Cardoso (2012). Las líneas temáticas de litigio escogidas por las ONG dependerían a su vez de los objetivos de las agencias financiadoras. Cfr. CARDOSO (2011). A largo plazo la concentración de casos por parte de las "ONG internacionales" podría ser revertida a través de la difusión del Fondo de Asistencia Legal para las Víctimas que fue creado el 3 de junio de 2008 por la Asamblea General de la OEA a través de la Resolución AG/RES. 2426. Se trata de un subsidio que la CIDH y la Corte IDH pueden otorgar a las presuntas víctimas que demuestren carecer de los recursos necesarios para sufragar los costos derivados de la tramitación de la petición y/o del litigio. Esta medida facilitaría el acceso de las víctimas al sistema interamericano de derechos humanos sin la intermediación de las "ONG internacionales".
} 
directas de litigio que implicaran cuestiones de género. Alegaban otras prioridades. Sea cuales fueran las razones, es más que plausible sostener que la llamada transversalización de la perspectiva de género no impactó en las agendas de litigio. Por ello, continúa siendo pertinente (y urgente) sostener una agenda de denuncias por violaciones a los derechos de las mujeres motorizada por defensoras y defensores de derechos humanos. ${ }^{8}$

A los efectos de orientar la interpretación de la variedad de documentos analizados, sostendremos que: a) el tratamiento de la violencia de género es claramente una prioridad para la CIDH y recientemente también para la Corte IDH. Sin embargo, y pese a todos los esfuerzos, la CIDH como la Corte IDH sostienen con matices un abordaje de la violencia de género limitado en lo concreto a la falta o insuficiencia de acceso a recursos judiciales efectivos, oportunos. b) No son enfáticos en la identificación de medidas transformadoras que ataquen los factores que sostienen la violencia de género. De lo contrario habrían producido documentos en los que trabajen, por ejemplo, las obligaciones de protección de los Estados respecto de los programas y publicidades emitidos por los medios masivos de comunicación que contienen violencia de género. ${ }^{9}$ A su vez, tampoco abundan los documentos en los que se trabaje la íntima relación entre pobreza y violencia de género o violencia contra las mujeres.

Para el análisis de los documentos a la luz de los anteriores puntos nos detendremos en la definición de violencia contra las mujeres o violencia de género. Luego analizaremos cómo los diversos órganos de protección han calificado desde el punto de vista jurídico los actos u omisiones que implican violencia como violaciones a los derechos humanos y como expresión de la desigualdad de poder. A su vez, seguiremos con la contracara de los derechos; nos dedicaremos a delimitar las obligaciones estatales para erradicar la violencia de género e incluso las que surgen de las partes de los documentos dedicadas a las medidas reparatorias. Finalizaremos con unas consideraciones que permitan realizar conjeturas sobre las proyecciones de las producciones del SIDH en materia de violencia de género.

8 Como sostiene Laudano luego de haber analizado las agendas de reclamos y litigio de tres importantes ONG en Argentina, v. LAUDANO (2006), pp. 147-160; LAUDANO (2010), pp. 88-110.

9 V. Laudano (2010). V. el "Informe sobre la publicidad televisiva y la violencia detrás de los estereotipos" realizado por la Universidad Nacional de Quilmes y el Observatorio de Género del Consejo Nacional de Mujeres (2011): a partir del monitoreo de las pautas publicitarias aparecidas en canales televisivos de aire argentinos entre enero y junio de 2011, se concluyó que la violencia mediática es elevada y constante, lo que favorece la reproducción de estereotipos de género. 


\subsection{Las producciones de la Comisión Interamericana de Derechos Humanos}

En cuanto a las estrategias de instalación del tema violencia de género, se diría que para la $\mathrm{CIDH}$, la transversalización ${ }^{10}$ va de la mano de las acciones específicas sobre género. La transversalización se puede observar, en especial, en los informes por países. ${ }^{11}$ Por el contrario, el abordaje específico prima en los informes por casos sobre violencia de género ${ }^{12} \mathrm{y}$ en los informes temáticos. ${ }^{13}$

De estos tres tipos de documentos surgen, en general, y como la propia CIDH lo advierte, ${ }^{14}$ seis estándares. Dos de ellos se refieren a cuestiones de calificación de la violencia. Así se remarca la íntima relación entre los problemas de la discriminación y la violencia contra las mujeres. Se califica a la violencia sexual como

10 Tramontana (2011), p. 144; Charlesworth (2005), pp. 1-18.

11 V., por ejemplo, Segundo Informe sobre la Situación de Derechos Humanos en el Perú (2000), párr. 18; Situación de los Derechos Humanos de la Mujer en Ciudad Juárez, México: el derecho a no ser objeto de violencia y discriminación (2003); Las Mujeres Frente a la Violencia y la Discriminación Derivadas del Conflicto Armado en Colombia (2006), párr. 29; Acceso a la Justicia e Inclusión Social: El Camino Hacia el Fortalecimiento de la Democracia en Bolivia (2007); El Derecho de las Mujeres a una Vida Libre de Violencia y Discriminación en Haití (2009), párr. 85; Informe sobre los Derechos de las Mujeres en Chile: La Igualdad en la Familia, el Trabajo y la Política (2009), párr. 43, entre otros.

12 Sobre decisiones de fondo, v.: Violencia contra las mujeres en el ámbito doméstico (CIDH, Informe No 54/01, Caso 12.051, Maria da Penha Fernandes (Brasil), 16 de abril de 2001; Informe No 80/11, Caso 12.626, Jessica Lenahan (Gonzales) y otros (Estados Unidos) (2011), 21 de julio de 2011; Violencia sexual como tortura (Informe No 5/96, Caso 10.970, Raquel Martín de Mejía (Perú) del 1o de marzo de 1996; Informe No 53/01, Caso 11.565, Ana, Beatriz y Cecilia González Pérez (México), 2 de abril de 2001; Violencia contra las mujeres en supuestos de discriminación interseccional (Informe No 53/01, Caso 11.565, Ana, Beatriz y Cecilia González Pérez (México), 2 de abril de 2001; Violencia cometida por particulares (Informe No 28/07, Casos 12.496-12.498, Claudia Ivette González y otras (México), 9 de marzo de 2007; Violencia y múltiples formas de discriminación (Informe No 89/08, Caso 12.580, Inés Fernández Ortega y otros (México), 30 de octubre de 2008; Informe No 36/09, Caso 12.579, Valentina Rosendo Cantú y otra (México), 27 de marzo de 2009. Sobre medidas cautelares en la materia, v. CIDH, Tránsito Jurado, María Eugenia González e integrantes de la Corporación Sisma Mujer, MC 99/10, 8 de abril de 2010; 14 Mujeres en situación de desplazamiento, MC 1/10, 25 de marzo de 2010; Claudia Julieta Duque Orrego y María Alejandra Gómez Duque, MC 339/09, 23 de noviembre de 2009; Miembros de la Liga de Mujeres Desplazadas y la Liga Joven de la LMD, MC 319/09, 18 de noviembre de 2009.

13 Acceso a la Justicia para las Mujeres Víctimas de Violencia en las Américas (2007, 2009); Acceso a Servicios de Salud Materna desde una Perspectiva de Derechos Humanos (2010); Estándares jurídicos vinculados a la igualdad de género y a los derechos de las mujeres en el sistema interamericano de derechos humanos: desarrollo y aplicación; Acceso a la Justicia de Mujeres Víctimas de Violencia Sexual en Mesoamérica (2011); La situación de las personas afrodescendientes en las Américas (2011); El trabajo, la educación y los recursos de las mujeres: la ruta hacia la igualdad en la garantía de los derechos económicos, sociales y culturales (2011); Informe sobre Acceso a la Justicia para Mujeres Víctimas de Violencia Sexual: la Educación y la Salud (2011).

${ }_{14} \mathrm{CIDH}$, Acceso a la justicia para mujeres víctimas de violencia en Mesoamérica (2011), párr. 294. 
tortura cuando es realizada por agentes estatales. Los otros estándares se refieren a obligaciones estatales; en especial: la de cumplimiento inmediato de actuar con la debida diligencia requerida para prevenir, investigar y sancionar con celeridad y sin dilación todos los actos de violencia contra las mujeres cometidos por actores estatales como no estatales; la de garantizar la disponibilidad de mecanismos judiciales efectivos, adecuados e imparciales para víctimas de violencia contra las mujeres; la de "implementar acciones para erradicar la discriminación contra las mujeres y los patrones estereotipados de comportamiento que promueven su tratamiento inferior en sus sociedades"; "el deber de los órganos legislativos, ejecutivos y judiciales de analizar mediante un escrutinio estricto todas las leyes, normas, prácticas y políticas públicas que establecen diferencias de trato basadas en el sexo, o que puedan tener un impacto discriminatorio en las mujeres en su aplicación"; "de considerar en sus políticas adoptadas para avanzar la igualdad de género el particular riesgo a violaciones de derechos humanos que pueden enfrentar las mujeres por factores combinados con su sexo, como su edad, raza, etnia y posición económica, entre otros". ${ }^{15}$

Se diría que la imagen implícita que la Comisión tiene sobre protección de los derechos de las mujeres frente a la violencia es, en principio, la de la "exigibilidad judicial". De ahí que no se canse en reiterar el deber reforzado que tienen los Estados de garantizar recursos judiciales adecuados, suficientes, oportunos e idóneos para reclamar por actos u omisiones cometidos por violencia de género. Esta es una de sus premisas de trabajo: “... la administración de la justicia es la primera línea de defensa en la protección de los derechos humanos a nivel nacional, incluyendo los derechos de las mujeres". ${ }^{16}$ Así, ha demostrado recientemente especial interés por el análisis del impacto de los estándares del SIDH vinculado a asuntos de género en las sentencias judiciales de los tribunales de las Américas. Interpreta que el impacto de estos estándares tendría una proyección más allá de los casos particulares en los que recaen las sentencias: el Poder Judicial enviaría "mensajes sociales avanzando la protección y la garantía de los derechos humanos; en particular, las normas encaminadas a proteger a sectores en particular riesgo a sus derechos humanos como las mujeres" . ${ }^{17}$ Sin embargo, la CIDH relativiza su entusiasmo judicialista cuando agrega que: "El Poder Judicial es sólo un componente de una estructura estatal obligada a coordinar

$15 \mathrm{CIDH}$, Acceso a la justicia para mujeres víctimas de violencia en Mesoamérica (2011), párr. 294.

$16 \mathrm{CIDH}$, El trabajo, la educación y los recursos de las mujeres: la ruta hacia la igualdad en la garantía de los derechos económicos, sociales y culturales (2011), párr. 168.

17 Con cita de CIDH, Informe No 54/01, Caso 12.051, Maria da Penha Fernandes (Brasil) (2001). 
los esfuerzos de todos sus sectores para respetar y garantizar los derechos humanos en general; principio que acarrea obligaciones para los Estados que sobrepasan las intervenciones de su Poder Judicial". ${ }^{18}$ En este sentido, es de esperar que el Informe titulado El trabajo, la educación y los recursos de las mujeres: la ruta hacia la igualdad en la garantía de los derechos económicos, sociales y culturales, de diciembre de 2011, inaugure una nueva etapa de la $\mathrm{CIDH}$ en cuestiones de género. En este informe reconoce expresamente que la pobreza persistente implica violencia de género.

\subsection{Las producciones de la Corte Interamericana de Derechos Humanos}

Aún no se ha sometido a consideración de la Corte IDH un pedido de opinión consultiva que entre de lleno a la cuestión de violencia contra las mujeres. Respecto de las sentencias se destacan ${ }^{19}$ sobre: a) definición de violencia sexual: Corte IDH, caso del Penal Miguel Castro Castro c. Perú (2006); b) violencia contra las mujeres perpetrada por particulares: Corte IDH, caso González y otras ("Campo Algodonero") c. México (2009); c) violencia contra las mujeres en un contexto de conflicto armado: Corte IDH, caso de la Masacre de Las Dos Erres c. Guatemala (2009); d) violencia sexual contra mujeres indígenas, barreras particulares en el acceso a la justicia: Corte IDH, caso Fernández Ortega y otros c. México (2010); e) múltiples formas de discriminación: Corte IDH, caso Rosendo Cantú y otra c. México (2010). ${ }^{20}$

La enumeración de sentencias de la Corte IDH sobre violencia contra las mujeres es a todas luces menor si se la compara con las producciones de la CIDH. Esto se puede deber a: a) la reticencia de la CIDH en la remisión de casos sobre violencia de género a la Corte IDH; b) la subrepresentación de las mujeres en ambos órganos; ${ }^{21}$

$18 \mathrm{CIDH}$, Estándares jurídicos vinculados a la igualdad de género y a los derechos de las mujeres en el sistema interamericano: desarrollo y aplicación (2011), párr. 8.

19 Esto no quiere decir que no le hayan llegado con anterioridad denuncias en las que pudo desplegar una perspectiva de género, sino que en reiteradas ocasiones desaprovechó la oportunidad, v. 1) Carpio Nicolle c. Guatemala (2004) 22/11/2004; 2) Las hermanas Serrano Cruz c. El Salvador (2005) 1/3/2005; 3) Escué Zapata c. Colombia (2007) 4/7/2007; 4) Blanca Kawas Fernández c. Honduras (2009) 3/4/2009, sobre el asesinato de una mujer que presidía una ONG ambiental; 5) Reverón Trujillo c. Venezuela (2009) 3/6/2009: destitución arbitraria de una jueza. Aborda el principio de igualdad de trato y de oportunidades (párrs. 7375 y 131-141), entre otros.

20 Probablemente, a esta lista se agregue una sentencia de la Corte IDH sobre el caso "María Isabel Véliz Franco c. Guatemala" sometido por la CIDH ante la Corte el 3/5/2012. Se trata del secuestro y posterior asesinato de una niña de 15 años en Guatemala, en un contexto de asesinatos masivos a mujeres en aquel país.

21 Sonia Picado Sotela fue la primera mujer integrante de la Corte IDH en carácter de Jueza (período 19891994). Pasarían diez años (2004) hasta que asumiera nuevamente una mujer, Cecilia Medina Quiroga, que además alcanzó el cargo de Presidenta de la Corte (2008-2009). En el año 2007 se incorporaron las Juezas 
c) la reevaluación que realiza la Corte IDH de la prueba presentada previamente ante la $\mathrm{CIDH}$, lo que incluye el testimonio de las víctimas. Cuando se trata de violencia de género, y específicamente violencia sexual, puede ocurrir que las víctimas opten por no remitir el caso a la instancia contenciosa, pues brindar nuevamente el testimonio en estos casos podría producirles un fuerte daño emocional y psicológico. ${ }^{22}$

Pero, además, se debe a la mirada estrecha de la Corte IDH para enfocar algunos casos desde la perspectiva de la violencia de género. Así, en tiempos tempranos desaprovechó dos oportunidades únicas para desarrollar la perspectiva de género. La primera vez fue en 1984 cuando ejerció su competencia consultiva. En esta opinión consideró discriminatorio el trato jurídico diferenciado que se establecía en la Constitución de Costa Rica para las mujeres extranjeras que contraían matrimonio con hombres costarricenses (Opinión Consultiva No 4). La segunda vez fue en 2003, en ocasión de la Opinión Consultiva No 18 sobre derechos de los migrantes. En esta oportunidad desarrolló ampliamente el principio de igualdad y no discriminación como expresiones del jus cogens. Sin embargo, en ninguna de las dos oportunidades relacionó patrones de cultura dominantes que implicaran discriminación contra las mujeres. Así, y claramente por contraste con estos pronunciamientos, el año 2006 -con el caso Castro Castro- marca el camino de ida (y es de esperar sin retorno ${ }^{23}$ de la Corte IDH hacia la incorporación de la perspectiva de género.

\section{DeFinición DE VIOlENCIA CONTRA LAS MUJERES}

\subsection{Definiciones en los Instrumentos Internacionales de DD.HH.}

Por su alcance internacional, es pertinente que tanto la Comisión como la Corte IDH consideren en sus producciones la Recomendación No 19 (1992) en

Margarette May Macaulay y Rhadys Abreu Blondet, cuyos mandatos finalizaron en el año 2012. En la actualidad (abril de 2013), la Corte no está integrada por ninguna mujer.

22 Salvioli señala que en el caso de Dianna Ortiz, aun cuando la CIDH consideró que el caso ameritaba su sometimiento ante la Corte, el representante legal de la víctima solicitó que no fuera remitido, pues sería traumático que relatara nuevamente el calvario sufrido (había sufrido torturas y violaciones sexuales reiteradas por parte de miembros de las fuerzas de seguridad de Guatemala). Por esta razón, a pesar de que la Corte tiene plenas facultades de revisar lo actuado por la CIDH, si evaluara el procedimiento realizado en la instancia previa, algunas pruebas como los testimonios serían innecesarios en ciertos casos, evitando a las víctimas revivir situaciones profundamente traumáticas. Cfr. SALVIOLI (1997). V. CIDH, "Informe 31/93", Caso 10.526, Dianna Ortiz (Guatemala), 16 de octubre de 1996.

23 V. los casos trabajados en el apartado 2.3.1. de este trabajo. 
la cual el CEDAW definió el concepto "Violencia contra la Mujer",24 aplicable tanto a la proveniente de la violencia estatal como a la realizada por particulares.

Por su parte, en el SIDH es de suma importancia la Convención Interamericana para Prevenir, Sancionar y Erradicar la Violencia contra la Mujer o más conocida como Convención de "Belém do Pará", adoptada el 9/6/1994, que define la violencia contra las mujeres como:

"Se entenderá que violencia contra la mujer incluye la violencia física, sexual y psicológica:

a. que tenga lugar dentro de la familia o unidad doméstica o en cualquier otra relación interpersonal, ya sea que el agresor comparta o haya compartido el mismo domicilio que la mujer, y que comprende, entre otros, violación, maltrato y abuso sexual.

b. que tenga lugar en la comunidad y sea perpetrada por cualquier persona y que comprende, entre otros, violación, abuso sexual, tortura, trata de personas, prostitución forzada, secuestro y acoso sexual en el lugar de trabajo, así como en instituciones educativas, establecimientos de salud o cualquier otro lugar, y

c. que sea perpetrada o tolerada por el Estado o sus agentes, dondequiera que ocurra”.

La definición es amplia y contempla el sufrimiento físico y/o psíquico, como así también puede incluir el daño, aunque no le produzca a las mujeres sufrimiento, pero sí una violación a los derechos por razones de violencia de género. A su vez, rompe con la invisibilización de la violencia en el ámbito privado: es claro que aunque la violencia se produzca, por ejemplo, en el ámbito doméstico, familiar o de confianza, sigue siendo violencia y no cae bajo el manto exculpatorio de la "privacidad" del hogar. Por ello, en cuanto a los ámbitos en tren de enumeración

24 “6. El artículo 1 de la Convención define la discriminación contra la mujer. Esa definición incluye la violencia basada en el sexo, es decir, la violencia dirigida contra la mujer porque es mujer o que la afecta en forma desproporcionada. Incluye actos que infligen daños o sufrimientos de índole física, mental o sexual, amenazas de cometer esos actos, coacción y otras formas de privación de la libertad. La violencia contra la mujer puede contravenir disposiciones de la Convención, sin tener en cuenta si hablan expresamente de la violencia. 7. La violencia contra la mujer, que menoscaba o anula el goce de sus derechos humanos y sus libertades fundamentales en virtud del derecho internacional o de los diversos convenios de derechos humanos, constituye discriminación, como la define el artículo 1 de la Convención. Esos derechos y libertades comprenden: a) El derecho a la vida; b) El derecho a no ser sometido a torturas o a tratos o penas crueles, inhumanos o degradantes; c) El derecho a protección en condiciones de igualdad con arreglo a normas humanitarias en tiempo de conflicto armado internacional o interno; d) El derecho a la libertad y a la seguridad personales; e) El derecho a igualdad ante la ley; f) El derecho a igualdad en la familia; g) El derecho al más alto nivel posible de salud física y mental; h) El derecho a condiciones de empleo justas y favorables. 8. La Convención se aplica a la violencia perpetrada por las autoridades públicas. Esos actos de violencia también pueden constituir una violación de las obligaciones del Estado en virtud del derecho internacional sobre derechos humanos u otros convenios, además de violar la Convención". 
ejemplificativa (no taxativa), podría pensarse en el familiar, doméstico, escolar, laboral, policial, de conflicto armado, de detención, judicial, de cualquier agencia estatal, recreativo, educativo, sanitario, entre otros. En cuanto a las manifestaciones de la violencia contra las mujeres abarca -nuevamente en clave ejemplificativa- la violencia en las relaciones interpersonales (física, sexual, psicológica), la violencia sexual, la trata de personas, las esterilizaciones forzadas, la falta de acceso a métodos anticonceptivos, el acoso o asedio laboral, entre otras. ${ }^{25}$

Chinkin marca una limitación de la definición de la Convención de Belém do Pará: no trataría expresamente el daño económico, como sí lo hacen el Protocolo a la Carta Africana de Derechos Humanos y de los Pueblos sobre los Derechos de las Mujeres en África, de 2003, en el artículo 1, párrafo j, y el Convenio Europeo para la Lucha contra la Violencia Doméstica hacia la Mujer y su Prevención, de 2011, en el artículo 3, párrafo a. En este último instrumento la violencia económica está contenida en la definición de violencia doméstica, donde se la considera relacionada con la violencia psicológica. En la legislación interna de los países de la región interamericana, la Ley de protección integral para prevenir, sancionar y erradicar la violencia contra las mujeres en los ámbitos en que desarrollen sus relaciones interpersonales (Ley argentina No 26.485 [2009]), es señalada por Chinkin como un avance al respecto, ya que alcanza todas las formas de violencia de género, incluso la violencia física, psicológica, sexual, económica y patrimonial. Sin embargo, como remarca Chinkin, los tribunales no siempre aplican una definición amplia de violencia contra las mujeres, aunque ésta se encuentre contemplada en la legislación nacional. ${ }^{26}$

En la definición, la referencia al género nos permite pensar que la violencia contra las mujeres está vinculada a la desigual distribución del poder y a las relaciones asimétricas que se establecen entre varones y mujeres en las sociedades. Estas relaciones asimétricas van en desmedro y perjuicio de todo lo que se atribuye a "lo femenino" y para subordinarlo a "lo masculino". Así, lo que diferencia a este tipo de violencia de otras formas de agresión y coerción es que el factor de riesgo o de vulnerabilidad es el solo hecho de ser "mujer". Justamente la posibilidad de ser "objeto" de violencia es lo que definiría el "ser" de las mujeres. ${ }^{27}$ Así, la violencia contra las mujeres no es sólo la física, la psíquica, la sexual, que millones de mujeres padecen a diario en el mundo; sino también la violencia simbólica

25 Gutiérrez Castañeda (2008), pp. 34-48; Gherardi (2012).

26 CHINkIN (2012).

27 Mackinnon (1989). 
que deviene de los roles estereotipados y características asignados culturalmente a las mujeres que restringen la autonomía y responden a una "violencia represiva y simbólica que se expresa en las limitaciones que se les imponen para acceder al trabajo, la participación social, los procesos de adopción de decisiones y al poder en todos sus niveles; esto constituye lo que se conoce como "violencia invisible", donde se inscriben las situaciones objetivas de agresiones ya sean físicas, psíquicas o sexuales, directas o indirectas" (Giberti y Fernández, 1989). Asimismo, la violencia puede estar dirigida directamente a la integridad física o psíquica de las mujeres o a un tercero (por ejemplo, daño o muerte a uno de sus hijos), o indirectamente a bienes materiales o inmateriales de las mujeres y para ejercer violencia contra ellas.

\subsection{Definiciones en las producciones de la CIDH}

En varios informes sobre países la CIDH ha concluido, en reiteradas oportunidades, que la violencia contra las mujeres es una manifestación de costumbres sociales que las relegan a una posición de subordinación y desigualdad, colocándolas, en consecuencia, en una situación de desventaja en comparación con el varón. Sin duda, esta caracterización se acerca, además, a la violencia simbólica que deviene de los roles estereotipados y características asignados culturalmente a las mujeres que restringen su autonomía. $\mathrm{La} \mathrm{CIDH}$ ha sostenido que la violencia contra las mujeres es una clara manifestación de la discriminación en razón de género; la ha descrito como un problema de derechos humanos; y se ha pronunciado sobre su impacto en el ejercicio de otros derechos. Ha reconocido las manifestaciones de la violencia contra las mujeres por agentes estatales, como por particulares bajo la tolerancia o aquiescencia del Estado en el contexto de conflictos armados. Las situaciones de violencia van desde la explotación, el abuso sexual, hasta la violación por los actores de los conflictos armados en su lucha por controlar territorio y recursos económicos.

En cuanto a las manifestaciones de la violencia contra las mujeres, la CIDH en su informe reciente sobre Acceso a Servicios de Salud Materna desde una Perspectiva de Derechos Humanos, identifica prácticas en la atención de servicios como el negar a una mujer la atención médica requerida cuando carece de la autorización de su pareja, o la esterilización forzada sin consentimiento, como ejemplos de formas de violencia contra las mujeres. ${ }^{28}$

28 CIDH, Acceso a Servicios de Salud Materna desde una Perspectiva de Derechos Humanos, 2010, párr. 75. 
En el caso "Maria da Penha v. Brasil" (Caso 12.051, Informe 54/2001) tuvo oportunidad de interpretar la norma de la Convención de Belém do Pará sobre violencia contra las mujeres. Sostuvo que: "El ámbito de aplicación de la CMV se refiere pues a situaciones definidas por dos condiciones: primero, que haya habido violencia contra la mujer tal como se describe en los incisos a) y b); y segundo que esa violencia sea perpetrada o tolerada por el Estado. La CMV protege entre otros los siguientes derechos de la mujer violados por la existencia de esa violencia: el derecho a una vida libre de violencia (artículo 3), a que se respete su vida, su integridad física, psíquica y moral y su seguridad personal, su dignidad personal, igual protección ante la ley y de la ley; y a un recurso sencillo y rápido ante los tribunales competentes, que la ampare contra actos que violen sus derechos (artículo 4(a) (b) (c) (d) (e) (f) y (g) y los consiguientes deberes del Estado establecidos en el artículo 7 de ese instrumento...”.

A su vez, en las decisiones sobre los casos de Raquel Martín de Mejía y de Ana, Beatriz y Celia González Pérez, la CIDH por primera vez abordó el concepto de violencia sexual como tortura y el acceso a la justicia para las víctimas, en el contexto del sistema de casos individuales. ${ }^{29}$ Sobre la violación sexual, la CIDH determinó que se habían "conjugado" los tres elementos enunciados en la Convención Interamericana para Prevenir y Sancionar la Tortura para probar la existencia de tortura: (1) "un acto a través del cual se inflijan a una persona penas y sufrimientos físicos y mentales"; (2) "cometido con un fin", y (3) "por un funcionario público o por una persona privada a instigación del primero". Al analizar estos elementos, la CIDH tuvo en cuenta el sufrimiento físico y psicológico causado por la violación sexual, la posibilidad de que la víctima sufriera "ostracismo" si denunciaba estos actos, y la forma en que la violación pudo haber sido perpetrada con la intención de castigar e intimidar a la víctima. ${ }^{30}$

29 En el caso particular de Raquel Martín de Mejía, la CIDH encontró al Estado peruano responsable por violaciones al derecho a la integridad personal. Los peticionarios alegaron ante la CIDH que el 15/6/1989, un grupo de personas armadas, con uniforme del ejército peruano, irrumpió en la casa de Raquel Martín y Fernando Mejía en Oxapampa acusándolos ser miembros del Movimiento Revolucionario Túpac Amaru. Luego de golpear y subir a Fernando Mejía a una camioneta propiedad del gobierno en presencia de su esposa, el grupo armado se marchó. Minutos después, la persona al mando de la operación regresó a la casa en dos ocasiones distintas, violando a Raquel Martín. Raquel Martín y su representante denunciaron los hechos, pero luego de iniciadas las investigaciones ordenadas por el Fiscal Provincial de Oxapampa, la víctima recibió amenazas anónimas de muerte si continuaba con la investigación; CIDH, Informe No 5/96, Caso 10.970, Raquel Martín de Mejía (Perú), del 1o de marzo de 1996.

30 CIDH, Informe No 5/96, Caso 10.970, Raquel Martín de Mejía (Perú), del 1º de marzo de 1996. 
En el caso paradigmático de Maria da Penha Maia Fernandes, ${ }^{31}$ la Comisión aplicó la Convención de Belém do Pará y calificó a la violencia contra las mujeres cometidas en el ámbito doméstico como violencia de género. Sostuvo que el Estado había fallado en actuar con la debida diligencia requerida para prevenir, sancionar y erradicar la violencia doméstica, por no haber condenado ni sancionado en diecisiete años al agresor. ${ }^{32}$

Por último, la CIDH ha advertido, acertadamente, que en el caso de los Estados que no hayan ratificado la Convención Americana igualmente pueden ser denunciados por violencia contra las mujeres en virtud de la Declaración Americana. ${ }^{33}$ Así, las obligaciones que establece el artículo II de la Declaración comprenden la prevención y la erradicación de la violencia contra las mujeres como deber del Estado de eliminar formas directas e indirectas de discriminación. El Estado puede

31 En este caso, los peticionarios sostuvieron ante la CIDH que el Estado de Brasil había fallado por más de quince años en adoptar medidas efectivas y necesarias para procesar y sancionar a un agresor de violencia doméstica, pese a las denuncias efectuadas por la víctima. Maria da Penha padece de paraplejía irreversible y otras dolencias desde el año 1983 como resultado de las agresiones continuas de su entonces esposo. V. CIDH, Informe No 54/01, Caso 12.051, Maria Da Penha Fernandes (Brasil), 2001, párr. 60.

32 V. el caso de Ana, Beatriz y Celia González Pérez, la CIDH concluyó que el Estado había incumplido su obligación de garantía. En este caso, los peticionarios denunciaron ante la CIDH que las hermanas Ana, Beatriz y Celia González Pérez, mujeres indígenas Tzeltales del estado de Chiapas fueron separadas de su madre y detenidas ilegalmente, violadas y torturadas por un grupo de soldados durante dos horas. Los delitos permanecieron en la impunidad debido a que los casos fueron reenviados a la jurisdicción militar, fuero incompetente y carente de la imparcialidad para investigar y, en su caso, sancionar de acuerdo con el debido proceso; CIDH, Informe No 53/01, Caso 11.565, Ana, Beatriz y Cecilia González Pérez (México), 2001, párr. 166.

33 En el caso de Jessica Lenahan (Gonzales) y otros (Estados Unidos), la CIDH se pronunció sobre la discriminación contra las mujeres bajo la Declaración Americana y su vínculo estrecho con la violencia contra la mujer. En este caso, los peticionarios sostienen que el Estado violó varias disposiciones de la Declaración Americana por no actuar con la debida diligencia para proteger a Jessica Lenahan y a sus hijas contra actos de violencia doméstica cometidos por su ex marido y el padre de las niñas, pese a haberse dictado una orden de protección contra el ex cónyuge y a favor de la señora Lenahan; eventos que resultaron en la muerte de las niñas. En el informe, la CIDH fijó estándares importantes, estableciendo: a) que los Estados están obligados bajo la Declaración Americana a dar efecto legal a los deberes contenidos en su artículo II y su obligación de no discriminar; b) que las obligaciones bajo el artículo II de la Declaración Americana comprenden la prevención y la erradicación de la violencia contra la mujer como un componente crucial del deber estatal de eliminar formas directas e indirectas de discriminación; c) que en ciertas circunstancias el Estado puede incurrir en responsabilidad por no proteger a las mujeres de actos de violencia doméstica perpetrados por particulares; y d) que cuando un Estado no cumple con su obligación de proteger a las mujeres de la violencia doméstica de acuerdo a lo dispuesto en el artículo II de la Declaración Americana, esto puede también dar lugar en ciertos casos a una violación del derecho a la vida consagrado en el artículo I de la Declaración Americana y al deber de otorgar una protección especial, establecido en el artículo VII del mismo instrumento. 
incurrir en responsabilidad por no proteger a las mujeres de actos de violencia doméstica perpetrados por particulares, como así lo señaló en el reciente caso de Jessica Lenahan (Gonzales) contra EE.UU. 34

\subsection{Definiciones en las sentencias de la Corte IDH}

La Corte IDH utilizó expresamente la definición de violencia contra las mujeres de la Convención de Belém do Pará. Al respecto, se puede clasificar la jurisprudencia de la Corte IDH en dos grandes grupos.

Antes de 2006, la Corte IDH claramente desaprovecha pronunciarse sobre el tema en reiteradas oportunidades. En Loayza Tamayo c. Perú (1997) se resistió a ver el caso desde la perspectiva de género: en especial, se mostró poco flexible respecto de la prueba de violación de una mujer por agentes estatales. ${ }^{35}$ Consideró que no podían probarse las violaciones sexuales que sufrió Loayza Tamayo, a pesar de los testimonios que estaban incluidos en la sentencia de personas que presenciaron la situación y del testimonio de la propia víctima. ${ }^{36}$ Esta actitud evasiva de la Corte IDH es abandonada con acierto, por ejemplo, en el caso Fernández Ortega (2010), en el que estableció que "le resulta evidente que la violación sexual es un tipo particular de agresión que, en general, se caracteriza por producirse en ausencia de otras personas más allá de la víctima y el agresor o los agresores. Dada la naturaleza de esta forma de violencia, no se puede esperar la existencia de pruebas gráficas o documentales y, por ello, la declaración de la víctima constituye una prueba fundamental sobre el hecho". 37

En el caso Maritza Urrutia c. Guatemala, ${ }^{38}$ la Corte determinó que Maritza Urrutia sufrió violaciones a su integridad física y psíquica cometidas por agentes

$34 \mathrm{CIDH}$, Informe 80/11, Caso 12.626, Jessica Lenahan (Gonzales) y otros (Estados Unidos); v. Corte IDH. Interpretación de la Declaración Americana de los Derechos y Deberes del Hombre en el Marco del Artículo 64 de la Convención Americana sobre Derechos Humanos. Opinión Consultiva OC-10/89 del 14 de julio de 1989. Serie A No 10, párrs. 35-45; CIDH, Resolución 3/87, Caso 9.647, James Terry Roach y Jay Pinkerton (Estados Unidos), 22 de septiembre de 1987, Informe Anual de la CIDH 1986-87, párrs. 46-49. Cfr. Informe No 54/01, Caso 12.051, Maria da Penha Maia Fernandes (Brasil), Informe Anual de la CIDH 2001, párrs. 3, 37-44.

35 Corte IDH, Loayza Tamayo c. Perú (1997).

36 Corte IDH, Loayza Tamayo c. Perú (1997), Sentencia de 17 de septiembre de 1997, párr. 58.

37 Corte IDH, Fernández Ortega (2010), párr. 100.

38 Corte IDH, Maritza Urrutia c. Guatemala (2003). En 1992 Maritza Urrutia, militante de la URNG (Unidad Revolucionaria Nacional Guatemalteca), fue secuestrada por miembros del Ejército y mantenida en cautiverio durante 8 días. 
estatales que fueron calificados como actos de tortura. Sin embargo, en ningún momento se analizó el impacto especial que pudo haber tenido en ella el ejercicio de la violencia. Por ejemplo, en relación con su maternidad: "sus secuestradores la presionaron para que les diera información, la amenazaron con que la iban a matar y le dijeron que tenían a su hijo en una habitación. Estaba muy nerviosa y alterada, especialmente porque pensaba que habían secuestrado a su hijo". 39 Recientemente, admitió el criterio cuando en el caso Gelman c. Uruguay (2011), la Corte IDH estableció que estos actos constituyen una de las formas más graves de violencia contra las mujeres.

La segunda etapa comienza -aunque tímidamente- con la sentencia sobre reparaciones en el caso Plan de Sánchez c. Guatemala (2004). ${ }^{40}$ En los hechos probados se hace referencia a la violencia sexual que sufrieron las mujeres de las comunidades mayas. En el análisis de los derechos violados, así como en las reparaciones, se toma en cuenta el distinto impacto que los hechos han tenido en las víctimas en virtud de su pertenencia a la población maya y se abordan los efectos colectivos generados a partir de la violencia contra las mujeres, sin embargo, no se incorpora un tratamiento diferenciado respecto de las víctimas mujeres, ello a pesar de que sostiene que: "Las mujeres que fueron objeto de violencia sexual por parte de agentes del Estado el día de la masacre y que sobrevivieron a la misma, continúan padeciendo sufrimientos por dicha agresión. La violación sexual de las mujeres fue una práctica del Estado, ejecutada en el contexto de las masacres, dirigida a destruir la dignidad de la mujer a nivel cultural, social, familiar e individual. Estas mujeres se perciben como estigmatizadas en sus comunidades y han sufrido por la presencia de los victimarios en las áreas comunes del municipio. Además, la impunidad en la que permanecen estos hechos ha impedido que las mujeres participen en los procesos de justicia”. ${ }^{41}$ A su vez, en la sentencia del caso de la Masacre de Mapiripán c. Colombia ${ }^{42}$ la Corte determinó que las mujeres sufren

\footnotetext{
39 Párr. 51.a.

40 En la demanda la Comisión alegó la denegación de justicia y otros actos de intimidación y discriminación realizados en perjuicio de los sobrevivientes y familiares de las víctimas de la masacre de 268 personas, en su mayoría miembros del pueblo indígena maya en la aldea Plan de Sánchez, ejecutada por miembros del Ejército de Guatemala y colaboradores civiles, bajo tutela del Ejército, el día domingo 18 de julio de 1982.

41 Corte IDH, Masacre de Plan de Sánchez c. Guatemala (2004), párr. 49.19; cfr. Voto concurrente de Sergio Ramírez, párr. 21.

42 Corte IDH, Masacre de Mapiripán c. Colombia (2005). En julio de 1997, fuerzas militares colombianas y paramilitares, con la aquiescencia y colaboración de funcionarios estatales, asesinaron y torturaron a 49 personas civiles -como mínimo- en la localidad de Mapiripán (Villavicencio, Colombia). Una porción
} 
una mayor vulnerabilidad en la situación de desplazamiento 43 forzado interno. Sin embargo, no realizó un mayor análisis sobre el impacto diferenciado que genera este tipo de violencia contra las mujeres.

\subsubsection{Definición de violencia desde una perspectiva de género}

Recién en el 2006 y en ocasión del Penal Miguel Castro Castro c. Perú44 la Corte IDH asume una perspectiva de género en casos sobre violencia contra las mujeres ocurrida durante un ataque al Penal en el que se encontraban detenidas, algunas de las cuales se encontraban incluso embarazadas ${ }^{45}$ : "[a]l analizar los hechos y sus consecuencias, la Corte tomará en cuenta que las mujeres se vieron afectadas por los actos de violencia de manera diferente a los hombres, que algunos actos de violencia se encontraron dirigidos específicamente a ellas y otros les afectaron en mayor proporción que a los hombres". ${ }^{46}$

Respecto de los hechos, estaba probado que durante el ataque al Penal que duró cuatro días, los internos recibieron un tratamiento inhumano violatorio del artículo 5 de la Convención Americana. ${ }^{47} \mathrm{La}$ Corte IDH agrega, en especial, que esta violación se vio agravada respecto de aquellos internos que se encontraban heridos y respecto de las mujeres que se encontraban embarazadas. Las mujeres embarazadas que vivieron el ataque experimentaron un sufrimiento psicológico adicional, ya que además de haber visto lesionada su propia integridad física, padecieron sentimientos de angustia, desesperación y miedo, por el peligro que corría la vida de sus hijos. Por ello, a la protección que otorga el artículo 5 de la $\mathrm{CADH}$ se le

importante de la población debió desplazarse forzadamente debido a la grave inseguridad y riesgos en los que se encontraban su vida y la de sus familiares.

43 La mayor vulnerabilidad de las mujeres en situación de desplazamiento forzado fue reiterada en Corte IDH, Masacres de Ituango c. Colombia (2006), párrs. 59, 96, 175, 212.

44 Corte IDH, Penal Miguel Castro Castro c. Perú (2006), párr. 223.

45 Los hechos se refieren a la ejecución del "Operativo Mudanza 1" dentro del Penal Miguel Castro Castro (a partir del 6 de mayo de 1992), durante el cual el Estado produjo la muerte de al menos 42 internos, hirió a 175 internos y sometió a trato cruel, inhumano y degradante a otros 322 internos. Asimismo, se refieren al trato cruel, inhumano y degradante experimentado por las víctimas con posterioridad al "Operativo Mudanza 1".

46 Corte IDH, Penal Miguel Castro Castro c. Perú (2006), párr. 223.

47 El ataque se inició contra el pabellón de mujeres 1A del Penal Miguel Castro Castro. Las mujeres que se encontraban en ese pabellón, incluidas las embarazadas, se vieron obligadas a huir del ataque en dirección al pabellón 4B. Este traslado fue especialmente peligroso, las internas sufrieron diversas heridas. Las prisioneras tuvieron que arrastrarse pegadas al piso y pasar por encima de cuerpos de personas fallecidas para evitar ser alcanzadas por las balas. Las mujeres embarazadas tuvieron que arrastrarse sobre su vientre. 
agrega, según la Corte, la del artículo 7 de la Convención de Belém do Pará48, que señala expresamente que los Estados deben velar porque las autoridades y agentes estatales se abstengan de cualquier acción o práctica de violencia contra las mujeres. 49

Asimismo, en el caso Castro Castro, la Corte IDH respecto del concepto de violencia contra las mujeres, se refirió a la Recomendación General No 19 del Comité para la Eliminación de la Discriminación contra la Mujer, que ha señalado que dicha discriminación incluye la violencia basada en el sexo, "es decir, la violencia dirigida contra la mujer porque es mujer o que la afecta en forma desproporcionada", y que abarca "actos que infligen daños o sufrimientos de índole física, mental o sexual, amenazas de cometer esos actos, coacción y otras formas de privación de la libertad". Y señaló que las detenidas "no deben sufrir discriminación, y deben ser protegidas de todas las formas de violencia o explotación". Asimismo, indicó que deben ser supervisadas y revisadas por oficiales femeninas y las mujeres embarazadas y en lactancia deben ser proveídas con condiciones especiales durante su detención.

\subsubsection{Violencia sexual}

La Corte IDH ha interpretado la violencia sexual como una "forma paradigmática" de violencia contra las mujeres; por ello, se considera que le ha dedicado buena parte de su atención argumentativa en su jurisprudencia sobre la materia. ${ }^{50}$ En Castro Castro, la Corte IDH brinda un concepto amplio de violencia sexual, que "se configura con acciones de naturaleza sexual que se cometen en una persona sin su consentimiento, que además de comprender la invasión física del cuerpo humano, pueden incluir actos que no involucren penetración o incluso contacto físico alguno". Así subsumió bajo el concepto de violencia sexual el hecho de

48 Un punto importante para destacar es que para la Corte IDH no fue óbice que el Estado demandado (Perú) para ese entonces no hubiese ratificado la Convención de Belém do Pará. La Corte aplicó el artículo 5 de la Convención Americana y fijó sus alcances, tomando en consideración como referencia de interpretación las disposiciones pertinentes de la Convención Interamericana para Prevenir, Sancionar y Erradicar la Violencia contra la Mujer, ratificada por Perú el 4 de junio de 1996, y la Convención sobre Eliminación de todas las Formas de Discriminación contra la Mujer, ratificada por Perú el 13 de septiembre de 1982, vigente en la época de los hechos. Interpretó que estos instrumentos complementan el corpus juris internacional en materia de protección de la integridad personal de las mujeres, del cual forma parte la Convención Americana; v. también párrs. 276 y 346 del caso del Penal Miguel Castro Castro.

49 Corte IDH, Penal Miguel Castro Castro c. Perú (2006), párr. 298.

50 V. esta afirmación en TRAMONTANA (2011), p. 162. 
"haber forzado a las internas a permanecer desnudas en el hospital, vigiladas por hombres armados, en el estado precario de salud en que se encontraban, [...], que les produjo constante temor ante la posibilidad de que dicha violencia se extremara aún más por parte de los agentes de seguridad, todo lo cual les ocasionó grave sufrimiento psicológico y moral, que se añade al sufrimiento físico que ya estaban padeciendo a causa de sus heridas". La Corte IDH aclara que la violación sexual no implica sólo una relación sexual sin consentimiento por vía vaginal, como se consideró tradicionalmente. Además, abarca actos de penetración anales sin consentimiento de la víctima. Agrega que en la perpetración del acto se pueden usar otras partes del cuerpo del agresor u objetos e incluye, por ejemplo, la penetración bucal del miembro viril. Indica, en el caso Fernández Ortega (2010), que para que exista violación sexual no se requiere resistencia física a la agresión, es suficiente que aparezcan elementos coercitivos en la conducta.

\subsubsection{Violación sexual cometida por agente estatal, tortura}

En Castro Castro fue un hecho probado que una detenida que fue trasladada al Hospital de la Sanidad de la Policía fue objeto de una "inspección” vaginal dactilar, realizada por varias personas encapuchadas a la vez, con suma brusquedad, bajo el pretexto de revisarla ${ }^{51}$. Esto configura violación sexual. En el mismo caso, la Corte determinó que las condiciones de detención ${ }^{52}$ de las mujeres y, en especial, de las madres y de aquellas en estado de embarazo, implicaron actos de tortura en violación del art. 5.2 de la CADH y de los arts. 1, 6 y 8 de la CIPST. Así, advirtió que la incomunicación severa tuvo efectos particulares en las internas madres. La imposibilidad de comunicarse con sus hijos ocasionó un sufrimiento psicológico adicional a las internas madres.

Además, la Corte indicó que cuando la violación sexual es cometida por un agente del Estado contra una mujer detenida, el acto es especialmente grave y reprobable, tomando en cuenta la vulnerabilidad de la víctima y el abuso de poder que despliega el agente. Además, se trata de un supuesto de tortura: "[...] tomando en cuenta lo dispuesto en el artículo 2 de la Convención Interamericana para Preveniry Sancionar la Tortura, este Tribunal concluye que los actos de violencia sexual a que fue sometida una interna bajo supuesta 'inspección' vaginal dactilar

51 Corte IDH, Penal Miguel Castro Castro c. Perú (2006), párrs. 50, 197 y 300.

52 Corte IDH, Penal Miguel Castro Castro c. Perú (2006), párr. 331: También afectó a las mujeres la desatención de sus necesidades fisiológicas. 
constituyeron una violación sexual que por sus efectos constituye tortura. Por lo tanto, el Estado es responsable por la violación del derecho a la integridad personal consagrado en el artículo 5.2 de la Convención Americana, así como por la violación de los artículos 1, 6 y 8 de la referida Convención Interamericana para Prevenir y Sancionar la Tortura [...]".53

Para la Corte IDH la violencia sexual implica, asimismo, una violación del artículo 11 de la CADH, es decir, de la protección de la honra y de la dignidad. Consideramos que debería interpretarse como una violación a la autonomía de las mujeres. Se trata así tanto de "una intromisión en su vida sexual" como de una violación a su "derecho a tomar libremente las decisiones respecto con quién tener relaciones sexuales", "las deliberaciones más personales e íntimas y sobre las funciones corporales básicas". ${ }^{54}$

Por lo demás, la Corte IDH no se ha mostrado lo suficientemente receptiva para calificar como tortura las violaciones a la integridad física, psíquica y moral de las mujeres víctimas de violencia sexual. Al respecto se pueden identificar, por lo menos, dos posiciones: la restrictiva y la amplia. La interpretación restrictiva parece surgir como la predominante a la luz de los casos analizados ${ }^{55}$. La Corte IDH toma la definición que surge de la Convención contra la Tortura y Otros Tratos o Penas Crueles, Inhumanos o Degradantes y en la Convención Interamericana para Prevenir y Sancionar la Tortura (CIPST), para las cuales, según interpretación de la Corte IDH, la participación estatal sería determinante. Por ello, un acto sólo sería "tortura" cuando el hecho haya sido realizado por un agente del Estado o con su aquiescencia o tolerancia y cumpla con los siguientes requisitos: i) haya sido intencional; ii) cause severos sufrimientos físicos o mentales, y iii) haya sido cometido con determinado fin o propósito. ${ }^{56}$ En el caso Fernández Ortega, la Corte determinó la presencia de los requisitos mencionados: "La señora Fernández Ortega estuvo sometida a un acto de violencia sexual y control físico del militar que la penetró sexualmente de manera intencional; su vulnerabilidad y la coerción

\footnotetext{
53 Corte IDH, Penal Miguel Castro Castro c. Perú (2006), párr. 312.

54 Corte IDH, Fernández Ortega c. México (2010), párr. 129; Rosendo Cantú y otra c. México (2010), párr. 119. Cfr. TPIY, Prosecutor c. Zejnil Delalic et al. (“Celebici Camp”), Caso No IT-96-21-T, 1998, párr. 492. También véase CIDH, Informe 53/01, Caso 11.565, Ana, Beatriz y Celia González (México), 2001, párr. 45. 55 V. Casos Fernández Ortega c. México, Rosendo Cantú c. México, González y otras (“Campo Algodonero”) c. México, Penal Miguel Castro Castro c. Perú.

56 Cfr. Corte IDH, Fernández Ortega c. México (2010), párr. 120; Rosendo Cantú y otra c. México (2010), párr. 110; Penal Miguel Castro Castro c. Perú (2006), párrs. 311 y 312. También v. CIDH, Informe 53/01, Caso 11.565, Ana, Beatriz y Celia González (México) (2001), párrs. 43-52.
} 
que el agente estatal ejerció sobre ella se reforzó con la participación de otros dos militares también armados, que agravaron el marco de violencia sexual ejercido contra la víctima, habiendo, incluso, otro grupo de militares que esperaron fuera de la casa”. Las circunstancias propias del caso agravaron el sufrimiento psicológico y moral de la víctima "ante la posibilidad de que fuera también violada sexualmente por ellos [los agentes de seguridad estatales] o por quienes se encontraban afuera de la casa". "De igual modo, la presencia de sus hijos en los momentos iniciales del hecho, así como la incertidumbre de si se encontraban en peligro o si habrían podido escapar, intensificaron el sufrimiento de la víctima”. ${ }^{57}$ En relación con el último requisito, la Corte sostuvo que la violación sexual cometida por los agentes militares tuvo por finalidad castigar a la señora Fernández Ortega frente a la falta de respuesta sobre la información solicitada. ${ }^{58}$

Por el otro lado, asoma la interpretación amplia sostenida por la jueza Cecilia Medina Quiroga en su voto relacionado en el caso Campo Algodonero. Medina critica así que la Corte IDH restrinja la calificación como tortura sólo a los actos que fueron perpetrados por agentes estatales. Su crítica se estructura en dos pasos. Así, primero, la condición necesaria para distinguir la tortura de otros tratamientos crueles, inhumanos o degradantes no es el elemento de la participación estatal. La condición esencial sería entonces la gravedad e intensidad del sufrimiento físico o psíquico ocasionado a las víctimas. Segundo, critica que la Corte IDH se incline por aquella interpretación que implica menor protección a los derechos humanos de las víctimas. Esto interpretamos en desmedro del principio pro-homine. Así, lo que la crítica de la jueza Medina permite leer entre líneas es que la Corte IDH ha dejado pasar una oportunidad inmejorable para calificar los actos cometidos contra las tres jóvenes mujeres asesinadas en Campo Algodonero como tortura. Las tres mujeres habían sufrido graves agresiones físicas. Las tres mujeres sufrieron con alto grado de probabilidad violencia sexual antes de morir. Como concluye Tramontana, la Corte evitó seguir la tendencia de otros órganos internacionales de protección de los derechos humanos que han abrazado la tesis amplia de interpretación de la tortura. Esto ha implicado en la práctica que los Estados fueran condenados aunque los actos fueran cometidos por agentes no estatales. 59

57 Cfr. Corte IDH, Fernández Ortega c. México (2010), párrs. 125-126.

58 Cfr. Corte IDH, Fernández Ortega c. México (2010), párr. 101, 127.

59 TRAMONTANA (2011), p. 166; marshall (2005), pp. 173 y ss. 
En Fernández Ortega y Rosendo Cantú, la Corte se pronuncia sobre la irrelevancia del lugar y de la frecuencia con la que fuera cometido el acto de violación sexual para constituir tortura: “... los elementos objetivos y subjetivos que califican un hecho como tortura no se refieren ni a la acumulación de hechos ni al lugar donde el acto se realiza". Es indiferente que "consista en un solo hecho u ocurra fuera de instalaciones estatales, como puede ser el domicilio de la víctima". ${ }^{60}$ Por último, cabe resaltar la importancia que adquiere la gravedad o intensidad del sufrimiento de la víctima que caracteriza a la tortura, a punto tal es relevante que no lo opaca por el hecho de que no haya existido rastros o prueba de lesiones o enfermedades físicas. ${ }^{61}$

\subsubsection{Feminicidio}

En el caso Campo Algodonero, la Corte IDH se refirió al feminicidio como emparentado al "homicidio de mujer por razones de género". La Corte no es precisa en su definición, ${ }^{62}$ pero varios interpretan, a partir de la sentencia, que para que se dé el supuesto se debe tratar: a) del asesinato de mujeres por el solo hecho de serlo, b) que los crímenes parezcan presentar altos grados de violencia, incluyendo sexual, c) de un contexto de una cultura de discriminación contra las mujeres, d) que incide tanto en los motivos como en la modalidad de los crímenes, e) así como en la respuesta de las autoridades frente a éstos: las respuestas son ineficientes y las actitudes indiferentes en cuanto a la investigación de dichos crímenes, que parecen haber permitido que se haya perpetuado la violencia contra la mujer en Ciudad Juárez (contexto de impunidad). ${ }^{63} \mathrm{~A}$ la luz de estos requisitos y teniendo en cuenta los hechos probados comentados en párrafos anteriores, la Corte IDH concluyó que los homicidios de las tres jóvenes fueron por razones de género y estuvieron enmarcados dentro de un reconocido contexto de violencia contra la mujer en Ciudad Juárez. ${ }^{64}$

60 Cfr. Corte IDH, Fernández Ortega c. México, párr. 128; Rosendo Cantú y otra c. México, párr. 118.

61 Corte IDH, Fernández Ortega c. México (2010), párr. 124.

62 Tramontana (2011), entre otros.

63 Corte IDH, González y otras (“Campo Algodonero”) c. México (2009), párrs. 164, 276.

64 Corte IDH, González y otras (“Campo Algodonero”) c. México (2009), párr. 231, entre muchos otros. 


\section{LA CALIFICACIÓN JURÍDICA DE LOS ACTOS U OMISIONES QUE IMPLICAN VIOLENCIA}

\subsection{La violencia contra las mujeres como violación del derecho a la integridad física, psíquica, en su caso, a la vida, a la honra y la dignidad}

En reiteradas sentencias, la Corte IDH calificó la violencia contra las mujeres como violaciones del derecho a la integridad física, psíquica y moral de las afectadas y de su derecho a la dignidad. A su vez, en algunos casos enfatizó que se trataba de violaciones del derecho a la vida de las mujeres, cuando la violencia implicó la muerte de las afectadas. Así en el caso Penal Miguel Castro Castro, la Corte analizó la situación de las detenidas heridas que fueron forzadas a permanecer desnudas y a realizar sus necesidades fisiológicas bajo la atenta mirada de agentes estatales de seguridad armados y determinó que aquello constituyó violencia sexual y un atentado directo "contra la dignidad de esas mujeres". ${ }^{65}$

En su sentencia reciente en el caso Gelman c. Uruguay, del 2011, la Corte IDH decidió sobre un caso en donde se alegaba la desaparición forzada de María Claudia García Iruretagovena de Gelman desde finales del 1976, quien fue detenida en Buenos Aires, mientras se encontraba en estado avanzado de embarazo. La Corte caracterizó los actos cometidos contra María Claudia García como una forma grave y reprochable de la violencia contra la mujer, perpetrada por agentes estatales argentinos y uruguayos, que afectaron gravemente su integridad personal y estuvieron claramente basados en su género.

\subsection{La violencia contra las mujeres como discriminación grave y estructural}

Tanto la Corte como la Comisión Interamericana sostuvieron que la discriminación contra las mujeres -definida en el artículo 2 de la CEDAW- comprende "toda diferencia de trato basada en el sexo que intencionalmente o en la práctica coloque a las mujeres en una situación de desventaja, e impida el pleno reconocimiento de sus derechos humanos en las esferas públicas y privadas". ${ }^{66}$

65 Corte IDH, Penal Miguel Castro Castro c. Perú, párr. 308; Gelman c. Uruguay, párr. 98; Rosendo Cantú c. México, párr. 108; Fernández Ortega c. México, párrs. 118 y 133; CIDH, Acceso a la justicia para mujeres víctimas de violencia sexual en Mesoamérica (2011), párr. 63.

$66 \mathrm{CIDH}$, Acceso a la Justicia para Mujeres Víctimas de Violencia Sexual: la Educación y la Salud (2011), párr. 24; Corte IDH, González y otras (“Campo Algodonero”) c. México (2009), párr. 394. 
La violencia de género fue vista, asimismo, como una forma grave de discriminación, como una de las formas más extremas y generalizadas, la cual impide y nulifica de forma severa el ejercicio de los derechos de las mujeres. En este sentido, el SIDH ha subrayado la fuerte vinculación entre los problemas de la discriminación y la violencia contra las mujeres. ${ }^{67}$ Para ello se tuvo en cuenta que esa discriminación habla de la permanencia, de la difusión y reproducción de los estereotipos de género, ${ }^{68}$ que "implica una distribución de facultades y derechos a favor del hombre y en detrimento de la mujer" ${ }^{69}$

La Corte IDH resalta en el caso Campo Algodonero la vinculación de la violencia de género con el incumplimiento del deber de no discriminación contenido en el artículo 1.1 de la CADH. Las autoridades estatales habrían minimizado los hechos y desacreditado las denuncias de los familiares de las víctimas bajo el pretexto de que aquellas eran "muchachitas" 'voladas' o que 'andaban con el novio'. La conducta de los funcionarios públicos, sumada a la inacción y la negligencia estatal en el desarrollo de la investigación, envía el mensaje de que la violencia contra las mujeres es tolerada, lo que favorece su perpetuación y la aceptación social del fenómeno, el sentimiento y la sensación de inseguridad en las mujeres, así como una persistente desconfianza de éstas en el sistema de administración de justicia. Esto le permite sostener a la Corte que la subordinación de la mujer se agrava cuando aquellos estereotipos "se reflejan, implícita o explícitamente, en políticas y prácticas, particularmente en el razonamiento y el lenguaje de las autoridades

67 V. en general, CIDH, Informe No 28/07, Casos 12.496-12.498, Claudia Ivette González y otros (México), de 2007; Informe No 54/01, Caso 12.051, Maria da Penha Maia Fernandes (Brasil), Informe Anual de la CIDH 2001; Acceso a la justicia para mujeres víctimas de violencia en las Américas (2007); Corte IDH, "Campo Algodonero" c. México (2009).

68 Sobre los estereotipos de género, vale destacar la sentencia dictada por la Corte IDH en el caso "Artavia Murillo y otros ("Fertilización in vitro") c. Costa Rica", del año 2012. Los hechos refieren a la sentencia de la Sala Constitucional de Costa Rica que había declarado en el año 2000 la inconstitucionalidad del decreto presidencial que había habilitado la práctica de la fecundación in vitro (FIV) en 1994. Aquí la Corte IDH incorporó explícitamente la perspectiva de género al análisis del caso y resaltó que la afectación a la integridad psicológica de las víctimas tuvo un impacto intensivo en las mujeres, pues (a) en sus cuerpos se concretan las intervenciones de las prácticas de FIV; y (b) existen estereotipos y mandatos sociales que asocian la condición de la mujer con la maternidad y provocan una marcada autoinculpabilización en las mujeres que padecen infertilidad. A pesar de incluir este tipo de análisis, la Corte no determinó que la prohibición del tratamiento de FIV constituyera una violación a la Convención de Belém do Pará, lo que tampoco fue solicitado por la CIDH ni por los representantes de las víctimas.

69 Comité para la Eliminación de la Discriminación contra la Mujer, Recomendación General No 28, Res. CEDAW/C/GC/28 (2010), 16 de diciembre de 2010, párr. 5. 
de policía judicial", lo que reproduce la violencia de género y constituye en sí misma una discriminación en el acceso a la justicia. ${ }^{70}$

Por último, en varias sentencias de la Corte IDH e Informes de la CIDH surge la advertencia sobre lo que se puede interpretar como discriminación interseccional. ${ }^{71}$ Es decir, cuando se produce una intersección entre la discriminación que sufren en razón del género y de otras variables constitutivas de la identidad, como sucede en el caso de las niñas, adolescentes o adultas mayores, indígenas, afrodescendientes, mujeres en situación de discapacidad, entre otras. Este enfoque supone que el colectivo de las mujeres no es un grupo homogéneo; por ello, requiere la inclusión en la reconstrucción de la situación de las víctimas "de otras variables relevantes que hacen que ciertas experiencias tengan un impacto diferenciado sobre algunos sectores en particular". Por ejemplo, en las sentencias de Inés Fernández Ortega y Valentina Rosendo Cantú c. México, la Corte IDH se refirió a obstáculos particulares que enfrentan las mujeres indígenas para acceder a la justicia, como el hablar un idioma distinto y el no tener acceso a intérpretes, y a la escasez de recursos económicos para acceder a un abogado, entre otros. Este problema en particular produce una desconfianza en el sistema de justicia y otras instancias públicas de protección. Para las mujeres indígenas, estas barreras serían particularmente graves, dado que también se enfrentan al rechazo y al ostracismo de sus comunidades cuando denuncian crímenes con causas específicas de género. ${ }^{72}$

En reiteradas ocasiones la Corte señaló que las niñas integran un grupo en situación de vulnerabilidad y, en consecuencia, los Estados tienen un deber reforzado de protección de sus derechos bajo el artículo 19 de la Convención Americana y a la luz del corpus juris en materia de derechos de la niñez y, en particular, de la Convención sobre Derechos del Niño. ${ }^{73}$ Por ello es que, en relación con las niñas,

70 Cfr. Corte IDH, González y otras ("Campo Algodonero") c. México, párrs. 400-401. También v. CIDH, Acceso a la justicia para mujeres víctimas de violencia sexual: la educación y la salud (2011), párr. 11; Acceso a la justicia para mujeres víctimas de violencia sexual en Mesoamérica (2011), párr. 42; El derecho de las mujeres a una vida libre de violencia y discriminación en Haití (2009), párr. 44; Informe 80/11, Caso 12.626, Jessica Lenahan (Gonzales) y otros (Estados Unidos) (2011), párr. 110; Informe 4/01, Caso 11.625, María Eugenia Morales de Sierra (Guatemala) (2001), párr. 52.

71 Crenshaw (1999), pp. 1241-1299; Muñoz Cabrera, Patricia (2011), p. 11.

72 V., asimismo, Corte IDH, Masacres de Río Negro c. Guatemala (2012), párr. 59; Gelman c. Uruguay, 2011, párrs. 1, 97-98, 149 y 153; Fernández Ortega y otros c. México (2010), párr. 78; Rosendo Cantú y otra c. México (2010), párr. 185; Comunidad Indígena Xákmok Kásek c. Paraguay (2010), párrs. 233-234, 152; Comité de Derechos Humanos, L.N.P. c. Argentina, Comunicación No 1610/2007 (2011), párr. 13.5.

73 Cfr. Corte IDH, Fornerón e Hija c. Argentina (2012), párr. 69; Atala Riffo e hijas c. Chile (2012), párr. 108; Gelman c. Uruguay (2011), párr. 121; González y otras (“Campo Algodonero”) c. México (2009), 
el deber de debida diligencia (artículo 9 de la Convención de Belém do Pará) implica que el Estado, frente a actos violentos, "debe tomar especial cuenta de la particular exposición a la violencia y actos discriminatorios que puede sufrir una mujer por su minoría de edad [...]". ${ }^{74}$ Esto implica para la Corte que el Estado debe facilitar su acceso a la justicia como así también debe crear los mecanismos y el entorno propicio para que puedan ejercer su derecho a ser escuchadas en un ámbito de seguridad y confidencialidad.

El Estado tiene obligaciones de tenor similar en relación con las mujeres y niñas que se encuentran en situación de discapacidad, lo que las expone a un riesgo mayor de sufrir múltiples formas de discriminación y de violencia. La $\mathrm{CIDH}$ determinó que el alcance de aquellas obligaciones emana del artículo 19 de la CADH y de la Convención de Belém do Pará, interpretadas a la luz de la Convención Interamericana para la Eliminación de todas las formas de Discriminación contra las Personas con Discapacidad y la Convención sobre los Derechos de Personas con Discapacidad. En este contexto, sostuvo que resulta fundamental que el Estado cumpla con sus obligaciones y, por ejemplo, diseñe planes de supervisión de los programas de cuidado de personas con discapacidad para garantizar así los derechos a la vida, la dignidad, la integridad, la intimidad, y prevenir los casos de explotación, abuso y violencia. ${ }^{75}$

\subsection{La relevancia del contexto en el que se comete la violencia contra las mujeres. Los conflictos armados: impacto en la discriminación}

La Corte IDH ha demostrado ser receptiva respecto del contexto en el que se cometen actos de violencia contra las mujeres, ya sea que se trate de conflictos armados o de ataques generalizados o sistemáticos. En el caso del Penal Miguel Castro Castro $^{76}$ interpreta que los actos de violencia cometidos contra las mujeres

\footnotetext{
párr. 408; Niñas Yean y Bosico c. República Dominicana (2005), párr. 134; Condición Jurídica y Derechos del Niño, Opinión Consultiva OC 17/02, párrs. 54 y 60. También v. CIDH, La situación de las personas afrodescendientes en las Américas (2011), párr. 76; Informe 87/10, Caso 12.649, Comunidad de Río Negro del pueblo indígena maya y sus miembros (Guatemala) (2010), párr. 259.

$74 \mathrm{CIDH}$, Acceso a la justicia para mujeres víctimas de violencia sexual: la educación y la salud (2011), párr. 57; cfr. Comité de los Derechos del Niño, Observación General No 13, 2011, párr. 19.

75 Cfr. CIDH, Acceso a la justicia para mujeres víctimas de violencia sexual: la educación y la salud (2011), párrs. 63 y ss.

76 Corte IDH, Penal Miguel Castro Castro (2006), párr. 402.
} 
en esos contextos constituyen "crímenes de lesa humanidad", cuya comisión es prohibida por una norma imperativa del Derecho Internacional. Esta calificación no es menor, ya que la prohibición de cometer estos crímenes es una norma de jus cogens y, por tanto, el Estado tiene el deber de no dejar impunes estos delitos. ${ }^{77}$ Esto le permite sostener a Tramontana que la Corte IDH se alinea con los más recientes avances de la práctica internacional en la materia. Sin embargo, esto no implica a su vez dejar de advertir que la Corte IDH ha dejado pasar importantes oportunidades para caracterizar los actos de violencia sexual cuando son utilizados para humillar a la parte contraria en los conflictos armados como "crímenes de guerra". ${ }^{78}$ La violencia que sufren las mujeres en los conflictos armados tiene un claro componente de género. ${ }^{79}$ En el informe sobre la violencia y la discriminación derivadas del conflicto armado colombiano, la Relatoría de los Derechos de la Mujer identificó diversas modalidades en las que impacta la violencia de manera diferenciada. Por un lado, frente a las estrategias de ataques que tienen por objetivo lesionar, aterrorizar y debilitar al "enemigo" y a su núcleo familiar o su comunidad, las mujeres no combatientes se convierten en víctimas directas o colaterales de la violencia física, psíquica y especialmente sexual en virtud de la relación afectiva que tienen con los combatientes (hijas, hermanas, madres, compañeras, esposas). La violación sexual se concibe como una táctica de humillación dirigida a los hombres -considerados tradicionalmente como los protectores de la sexualidad de las mujeres de la comunidad-que no han podido evitar la agresión sobre sus cuerpos. En el caso de la Masacre de Río Negro c. Guatemala, la Corte IDH señaló que la violación sexual cometida de manera sistemática por agentes estatales contra las mujeres de la comunidad tuvo graves efectos de carácter colectivo ${ }^{80}$ sobre la supervivencia étnica de la población indígena maya. ${ }^{81}$

La violencia en muchos casos trae aparejado el desplazamiento forzado que afecta gravemente a las mujeres por ser cabeza de familia y constituir más de la

77 Corte IDH, Penal Miguel Castro Castro (2006), párr. 404, y Masacre de Las Dos Erres c. Guatemala, 2009, párr. 140.

78 Tramontana (2011), p. 168; Copelon (2000), pp. 221 y ss.; McHenry (2002), pp. 1275 y ss.

$79 \mathrm{CIDH}$, Las mujeres frente a la violencia y la discriminación derivadas del conflicto armado interno en Colombia (2006), párr. 46.

80 Corte IDH, Masacre de Río Negro c. Guatemala (2012).

$81 \mathrm{CIDH}$, Informe 87/10, Caso 12.649, Comunidad de Río Negro del pueblo indígena maya y sus miembros (Guatemala) (2010), párrs. 288, 439. Se trata de la masacre planificada y ejecutada por el Estado guatemalteco en el contexto de una política de "tierra arrasada" dirigida contra el pueblo indígena maya. 
mitad de la población desplazada. ${ }^{82}$ Una de las consecuencias principales que sufren las mujeres desplazadas es "el cambio en la dinámica de los roles familiares y conyugales y responsabilidades debido a la muerte o pérdida del esposo o compañero, el trauma físico y psicológico producido por hechos de violencia y las amenazas padecidas, la necesidad de adaptarse social y económicamente a una nueva comunidad y el posible rechazo de ésta”. ${ }^{83}$

Las mujeres no son ajenas a los actos de discriminación en los que se cruzan los factores de género y de desplazamiento, lo que provoca enormes dificultades de toda índole, inclusive en el acceso a la ayuda humanitaria y a los servicios de salud. ${ }^{84} \mathrm{~A}$ su vez, en el caso de las mujeres afrodescendientes desplazadas, aquellos factores deben analizarse conjuntamente con la etnia y la situación de pobreza, origen de la discriminación histórica a la que han sido sometidos los integrantes de este grupo. A menudo padecen actos de racismo y estigmatización social por parte de las comunidades receptoras. ${ }^{85}$

Por otro lado, las mujeres y niñas inmersas en conflictos armados sufren un grave riesgo de ser reclutadas para realizar tareas militares, lo que en muchas ocasiones va acompañado de la explotación sexual por parte de los actores armados. La CIDH señala que los grupos paramilitares y las guerrillas, en la lucha por controlar territorios y recursos, imponen pautas de comportamiento social que refuerzan estereotipos de género afectando gravemente la seguridad y la autonomía de las mujeres y niñas. Los mecanismos de control incluyen la vigilancia regular del comportamiento y la vestimenta de las mujeres y de las adolescentes y el empleo de la violación sexual como castigo y ejemplo en advertencia general a la población femenina dentro de la comunidad. ${ }^{86}$

\section{LAS OBLIGACIONES DE RESPETAR, PROTEGER, GARANTIZAR DE LOS ESTADOS}

En reiterados documentos, informes, sentencias del SIDH se destaca el deber estatal de debida diligencia y su alcance para la prevención, investigación y

82 Cfr. Corte IDH, Masacres de Ituango c. Colombia (2006), párr. 212; Masacre de Mapiripán c. Colombia (2005), párr. 175.

83 Ídem.

${ }^{84}$ Cfr. CIDH, Las mujeres frente a la violencia y la discriminación derivadas del conflicto armado interno en Colombia (2006), párrs. 76 y ss.

85 Cfr. CIDH, La situación de las personas afrodescendientes en las Américas (2011), párrs. 70-76.

$86 \mathrm{Cfr}$. CIDH, Las mujeres frente a la violencia y la discriminación derivadas del conflicto armado interno en Colombia (2006), párr. 101. 
sanción de crímenes basados en el género, y el significado del derecho de acceso a la justicia de las víctimas de violencia. Este deber deviene de la interpretación del alcance del art. 1.1 de la CADH. Esta obligación estatal exige, en general, organizar el aparato estatal para asegurar el libre y pleno ejercicio de los derechos humanos de toda persona e implica el deber de prevenir, investigar, sancionar y reparar adecuadamente todas sus violaciones. Ahora bien, en los casos de violencia contra las mujeres este deber debe ser iluminado por el enfoque de género que surge de la norma más específica: la Convención de Belém do Pará. Así, la Corte habla no sólo de las obligaciones genéricas contenidas en la $\mathrm{CADH}$, sino también de unas "obligaciones reforzadas" de prevención e investigación, de conformidad con el estándar de "debida diligencia" establecido en el art. 7 (b) de la Convención contra la violencia hacia las mujeres: "En particular, deben contar con un adecuado marco jurídico de protección, con una aplicación efectiva del mismo y con políticas de prevención y prácticas que permitan actuar de una manera eficaz ante las denuncias. La estrategia de prevención debe ser integral, es decir, debe prevenir los factores de riesgo y a la vez fortalecer las instituciones para que puedan proporcionar una respuesta efectiva a los casos de violencia contra la mujer. Asimismo, los Estados deben adoptar medidas preventivas en casos específicos en los que es evidente que determinadas mujeres y niñas pueden ser víctimas de violencia". ${ }^{87}$

Así, interesa analizar cuándo se incurre en violación de la obligación estatal de debida diligencia. ${ }^{88} \mathrm{Al}$ respecto, resulta ilustrativa la sentencia de la Corte IDH en González y otras ("Campo Algodonero") c. México. En el caso se trata del accionar del Estado de México frente a las desapariciones y la posterior muerte de tres mujeres (de 17 años de edad, 20 años y 15 años de edad, respectivamente), en Ciudad Juárez. Las tres mujeres fueron reportadas por sus familiares como desaparecidas, sus cuerpos fueron encontrados semanas después en un Campo Algodonero en Ciudad Juárez con signos de violencia sexual y otras formas de abuso físico. Los familiares de las víctimas fueron constantemente maltratados, hostigados e intimidados por las autoridades estatales durante sus esfuerzos por impulsar y colaborar con las investigaciones. Los funcionarios no consideraron la búsqueda de las víctimas y la investigación sobre las muertes como una prioridad, debido a formas de discriminación contra las mujeres y estereotipos sobre

87 Corte IDH, González y otras (“Campo Algodonero”) c. México (2009), párr. 258.

88 Corte IDH, González y otras (“Campo Algodonero”) c. México (2009), párr. 252, sobre la obligación de prevenir como obligación de medio o comportamiento. Cfr. Corte IDH, Velásquez Rodríguez c. Honduras (1988), párr. 166; Perozo y otros c. Venezuela, 2009, párr. 149, y Anzualdo Castro c. Perú, 2009, párr. 63. 
su comportamiento y estilo de vida. ${ }^{89}$ Este caso es paradigmático por aplicación del estándar de la "debida diligencia" establecido en el artículo 7 de la CBDP, a fin de determinar el alcance del deber estatal de prevención de crímenes basados en el género. ${ }^{90}$

De la jurisprudencia del SIDH surge que la atribución de responsabilidad a un Estado por incumplir su deber de adoptar medidas de protección frente a actos de los particulares debe cumplir tres requisitos: a) el conocimiento por parte de las autoridades estatales de una situación de riesgo real e inmediato; b) para un individuo o grupo de individuos determinado, y c) la existencia de posibilidades razonables de prevenir o evitar ese riesgo. En esta línea de trabajo, la Corte IDH enfatiza el alcance de la obligación general de debida diligencia: se trata de un deber reforzado de prevención e investigación, de conformidad con el estándar de "debida diligencia" establecido en el art. 7 (b) de la Convención contra la violencia hacia las mujeres en contextos generalizados de violencia, desigualdad y vulneración. ${ }^{91}$ Entonces, la Corte IDH examina si las acciones alegadas por el Estado mexicano fueron suficientes y efectivas para prevenir las graves manifestaciones de la violencia contra las mujeres que se vivían en Ciudad Juárez en la época del caso. ${ }^{92}$

$89 \mathrm{CIDH}$, Demanda ante la Corte Interamericana de Derechos Humanos en el caso de Campo Algodonero contra los Estados Unidos Mexicanos (2007), párrs. 139-251; Corte IDH, González y otras ("Campo Algodonero") c. México (2009), párrs. 2-4.

90 Sobre la distinción de la doctrina del riesgo previsible, la doctrina del riesgo creado y la doctrina de la complicidad, v. Aвramovich (2010), p. 178: "La capacidad operativa del Estado de evitar que se materialice una situación de riesgo, no puede ser observada como si el Estado fuera un sujeto extraño al riesgo que debe reaccionar cuando lo conoce con lo que tiene disponible. El déficit de las políticas públicas y del sistema institucional determina en gran medida la capacidad de respuesta en la situación particular". V., asimismo, Abi-Mershed (2008), pp. 130 y ss.

91 En Campo Algodonero la Comisión y los representantes de las víctimas fueron (con matices) más enfáticos en la caracterización del contexto en el que ocurrieron los crímenes contra las tres mujeres. La Comisión alegó que el Estado "no adoptó medidas razonables para proteger la vida y prevenir los asesinatos" de las víctimas, "aunque tenía conocimiento del riesgo inminente que corrían de ser asesinadas por haber sido reportadas como desaparecidas a la fecha de los hechos". Señaló así que la información aportada por el Estado durante el trámite ante ella "no indica que se implementaron normas y prácticas orientadas a garantizar una orden de búsqueda inmediata ante las denuncias de desaparición, o que existieran disposiciones sancionadoras ante una deficiente respuesta de funcionarios estatales frente a las mismas". Por su parte, los representantes de las víctimas señalaron que "las autoridades mexicanas al momento de que ocurrieron las desapariciones de las víctimas tenían conocimiento de que existía un riesgo real e inmediato para la vida de estas", "[d]ebido a que, los casos aquí expuestos forman parte del patrón de violencia contra mujeres y niñas, y el Estado no tomó las medidas necesarias con la debida diligencia para evitarlo".

92 Corte IDH, González y otras (“Campo Algodonero”) c. México (2009), párr. 279. 
Si bien en este caso los actos de violencia no fueron perpetrados por el Estado, la Corte IDH igualmente encuentra al Estado responsable porque los agentes estatales incumplieron con la obligación de investigar con debida diligencia frente a las denuncias de desaparición de las víctimas. Para ello fue fundamental tener en cuenta el contexto de producción de los actos de violencia. Se trataba, según la Corte, de un contexto de fuerte violencia contra las mujeres. ${ }^{93}$ Así, dado el contexto del caso, las autoridades tenían conocimiento de que existía "un riesgo real e inmediato de que las víctimas fueran agredidas sexualmente, sometidas a vejámenes y asesinadas". Entonces, en este contexto de riesgo conocido por el Estado, ${ }^{94}$ éste no demostró haber adoptado medidas efectivas de prevención antes de noviembre de 2001 que redujeran los factores de riesgo para las mujeres. Así, es el Estado quien tiene la carga de demostrar que algo realizó y que esas acciones fueron suficientes. En este sentido, la Corte concluye que el Estado no demostró que las acciones realizadas (la creación de una Fiscalía, FEIHM, y algunas adiciones a su marco legislativo), por más que fueran necesarias y demostraran un compromiso estatal, fueran suficientes y efectivas para prevenir las graves manifestaciones de la violencia contra las mujeres que se vivía en Ciudad Juárez en la época del caso. Para evaluar la insuficiencia de las acciones, la Corte IDH desdobla el examen del cumplimiento del deber de prevención en dos momentos: a) antes de la desaparición de las víctimas y b) antes de la localización de sus cuerpos sin vida. a) Respecto del incumplimiento del deber de prevención antes de la desaparición de las víctimas, para que se determine se debe establecer que el Estado tenía conocimiento de un riesgo real e inmediato para las víctimas del caso y no basta, como en el presente, para la Corte que el Estado haya tenido conocimiento de una situación de riesgo para las mujeres. ${ }^{95}$ b) Respecto del incumplimiento del

93 Corte IDH, González y otras (“Campo Algodonero”) c. México (2009), párr. 278: "La Corte ha dado por probado y el Estado ha reconocido que en el año 2001 Ciudad Juárez vivía una fuerte ola de violencia contra las mujeres. Los hechos del caso revelan paralelos significativos con el contexto probado".

94 "A pesar de que el Estado tenía pleno conocimiento del riesgo que corrían las mujeres de ser objeto de violencia”, Corte IDH, González y otras (“Campo Algodonero”) c. México (2009), párr. 279.

95 Corte IDH, González y otras (“Campo Algodonero") c. México (2009): "Sobre el primer momento -antes de la desaparición de las víctimas- la Corte considera que la falta de prevención de la desaparición no conlleva per se la responsabilidad internacional del Estado porque, a pesar de que éste tenía conocimiento de una situación de riesgo para las mujeres en Ciudad Juárez, no ha sido establecido que tenía conocimiento de un riesgo real e inmediato para las víctimas de este caso. Aunque el contexto en este caso y sus obligaciones internacionales le imponen al Estado una responsabilidad reforzada con respecto a la protección de mujeres en Ciudad Juárez, quienes se encontraban en una situación de vulnerabilidad, especialmente las mujeres jóvenes y humildes, no le imponen una responsabilidad ilimitada frente a cualquier hecho ilícito en contra 
deber de prevención habiendo tomado conocimiento de la denuncia de desaparición de mujeres y antes del hallazgo, se evalúa en forma estricta: "En cuanto al segundo momento -antes del hallazgo de los cuerpos- el Estado, dado el contexto del caso, tuvo conocimiento de que existía un riesgo real e inmediato de que las victimas fueran agredidas sexualmente, sometidas a vejámenes y asesinadas. La Corte considera que ante tal contexto surge un deber de debida diligencia estricta frente a denuncias de desaparición de mujeres, respecto a su búsqueda durante las primeras horas y los primeros días. Esta obligación de medio, al ser más estricta, exige la realización exhaustiva de actividades de búsqueda".

En particular, es imprescindible: b.1) la actuación pronta e inmediata de las autoridades policiales, fiscales y judiciales, b.2) ordenando medidas oportunas y necesarias dirigidas a la determinación del paradero de las víctimas o el lugar donde puedan encontrarse privadas de libertad, b.3) deben existir procedimientos adecuados para las denuncias y que éstas conlleven una investigación efectiva desde las primeras horas. Las autoridades deben presumir que la persona desaparecida está privada de libertad y sigue con vida hasta que se ponga fin a la incertidumbre sobre la suerte que ha corrido. La Corte IDH concluye que el Estado "no actuó con la debida diligencia requerida para prevenir adecuadamente las muertes y agresiones sufridas por las víctimas y que no actuó como razonablemente era de esperarse de acuerdo a las circunstancias del caso para poner fin a su privación de libertad. Este incumplimiento del deber de garantía es particularmente serio debido al contexto conocido por el Estado -el cual ponía a las mujeres en una situación especial de vulnerabilidad-y a las obligaciones reforzadas impuestas en casos de violencia contra la mujer por el artículo 7.b de la Convención Belém do Pará", ${ }^{96}$ ya que de acuerdo con la aplicación de los estándares b.1), b.2) y b.3): b.1) El Estado no actuó con prontitud dentro de las primeras horas y días luego de las denuncias de desaparición, dejando perder horas valiosas. b.2) En el período entre las denuncias y el hallazgo de los cuerpos de las víctimas, el Estado se limitó a realizar formalidades y a tomar declaraciones que, aunque importantes, perdieron su valor una vez éstas no repercutieron en acciones de búsqueda específicas. b.3) Además, las actitudes y declaraciones de los funcionarios hacia los familiares de las víctimas que daban a entender que las denuncias de desaparición no debían

de ellas. Finalmente, la Corte no puede sino hacer presente que la ausencia de una política general que se hubiera iniciado por lo menos en 1998 -cuando la CNDH advirtió del patrón de violencia contra la mujer en Ciudad Juárez-, es una falta del Estado en el cumplimiento general de su obligación de prevención".

96 Corte IDH, González y otras (“Campo Algodonero”) c. México (2009), párr. 284. 
ser tratadas con urgencia e inmediatez llevan al Tribunal razonablemente a concluir que hubo demoras injustificadas luego de las presentaciones de las denuncias de desaparición. En suma, el Estado (México) no demostró haber adoptado las medidas razonables, conforme a las circunstancias que rodeaban a los casos, para encontrar a las víctimas con vida. Además, en general, la Corte considera que el Estado no demostró haber adoptado normas o implementado las medidas necesarias, conforme al artículo 2 de la Convención Americana y al artículo 7.c de la Convención Belém do Pará, que permitieran a las autoridades ofrecer una respuesta inmediata y eficaz ante las denuncias de desaparición y prevenir adecuadamente la violencia contra la mujer. Tampoco demostró haber adoptado normas o tomado medidas para que los funcionarios responsables de recibir las denuncias tuvieran la capacidad y la sensibilidad para entender la gravedad del fenómeno de la violencia contra la mujer y la voluntad para actuar de inmediato.

Por lo demás, como se señaló a lo largo de este capítulo, para el SIDH el acceso de las víctimas a la justicia es de especial importancia e incluso cumpliría finalidades transformativas y reparadoras. Este punto es tratado, asimismo, en la paradigmática sentencia en el caso Campo Algodonero cuando se detiene en el impacto de los estereotipos de género en la investigación de los casos de violencia contra las mujeres. ${ }^{97}$ Éste se refleja en la actitud indiferente de los agentes estatales frente a las denuncias de desaparición de las tres víctimas en el contexto de la "cultura de discriminación" existente en Ciudad Juárez. ${ }^{98}$ Además, resulta esclarecedor cuando la Corte IDH evalúa los efectos de la impunidad de los delitos cometidos, ya que "envía el mensaje de que la violencia contra la mujer es tolerada, lo que favorece su perpetuación y la aceptación social del fenómeno, el sentimiento y la sensación de inseguridad en las mujeres, así como una persistente desconfianza de éstas en el sistema de administración de justicia”.

$\mathrm{Al}$ respecto, el Tribunal resalta lo precisado por la CIDH en su informe temático sobre "Acceso a la Justicia para Mujeres Víctimas de Violencia" en el sentido de que "[l]a influencia de patrones socioculturales discriminatorios puede dar como resultado una descalificación de la credibilidad de la víctima durante el proceso penal en casos de violencia y una asunción tácita de responsabilidad de ella por los hechos, ya sea por su forma de vestir, por su ocupación laboral, conducta

97 V. Corte IDH, Fernández Ortega y otros c. México (2010), párr. 194, y Rosendo Cantú y otra c. México (2010), párr. 178.

98 Corte IDH, González y otras (“Campo Algodonero”) c. México (2009), párr. 400. V. Rosendo Cantú y otra c. México (párr. 93) y Fernández Ortega y otros c. México (párr. 78). 
sexual, relación o parentesco con el agresor, lo cual se traduce en inacción por parte de los fiscales, policías y jueces ante denuncias de hechos violentos. Esta influencia también puede afectar en forma negativa la investigación de los casos y la valoración de la prueba subsiguiente, que puede verse marcada por nociones estereotipadas sobre cuál debe ser el comportamiento de las mujeres en sus relaciones interpersonales". 99

Por todo ello, resulta de interés aplicar las razones del deber reforzado a las obligaciones de investigación, la que debe ser realizada entonces "con vigor e imparcialidad, teniendo en cuenta la necesidad de reiterar continuamente la condena" de la violencia de género por parte de la sociedad y para mantener la confianza de las afectadas en la habilidad de las autoridades de protegerlas de la amenaza de violencia de género ${ }^{100}$. Esta cita, que sigue apostando a la confianza en el efecto transformador del acceso a la justicia de las víctimas, nos invita a adentrarnos en el último punto de nuestro trabajo: las medidas reparatorias. Éstas deberían ser pensadas, además, con carácter transformador si es que se quiere desterrar el patrón de cultura dominante que asocia la subordinación de la mujer a prácticas basadas en estereotipos de género "socialmente dominantes y socialmente persistentes, condiciones que se agravan cuando los estereotipos se reflejan, implícita o explícitamente, en políticas y prácticas, particularmente en el razonamiento y el lenguaje de las autoridades de policía judicial, como ocurrió en el presente caso. La creación y uso de estereotipos se convierte en una de las causas y consecuencias de la violencia de género en contra de la mujer". ${ }^{101}$

\section{CONSIDERACIONES INTERMEDIAS}

Las producciones de la Corte IDH y de la CIDH dan cuenta, por un lado, de la inclusión de una perspectiva de género. ${ }^{102}$ Esto es claro, por ejemplo, en el tratamiento de los hechos en las sentencias trabajadas. La Corte IDH se preguntó cómo las prácticas violatorias de los derechos impactaban en forma diferenciada en la situación de las mujeres, esto aparece en forma contundente en el tratamiento

$99 \mathrm{CIDH}$, Acceso a la justicia para las mujeres víctimas de violencia en las Américas (2007).

100 Párr. 293 en aplicación analógica de los deberes reforzados de investigación cuando se trata de crímenes realizados por racismo, en TEDH, Angelova e Iliev c. Bulgaria, 2007, para. 98.

101 Corte IDH, González y otras (“Campo Algodonero”) c. México (2009), párr. 401.

102 Sobre algunos criterios para detectar cuándo una sentencia incluye una perspectiva de género o feminista, v. Hunter (2010: 35). 
de los hechos del caso Castro Castro. Asimismo, incluyó otra herramienta característica de la perspectiva de género: la contextualización y particularización de la situación de las mujeres que fueron víctimas de actos de violencia de género; esto surge del tratamiento de las cuestiones en el caso Campo Algodonero cuando se refirió a la situación de las mujeres en Ciudad Juárez y al obrar prejuicioso de los agentes policiales. Además, ambos órganos aplicaron material normativo construido con perspectiva de género: la CEDAW, la Recomendación No 19 del Comité y la Convención de Belém do Pará. Para la Corte IDH y la Comisión, éstas son las directrices a partir de las cuales deben interpretarse las disposiciones de la $\mathrm{CADH}$ y de diversos instrumentos americanos, como la Declaración Americana de los Derechos y Deberes del Hombre, la CIPST y el Protocolo de San Salvador, en materia de violencia contra las mujeres. Ello les ha permitido, por ejemplo, construir con límites abiertos los conceptos de "violencia doméstica" y de "violencia sexual", así como el de "debida diligencia" en lo concerniente a la responsabilidad estatal.

Por otro lado, en cambio, la perspectiva de género de la Corte IDH aplicada en las sentencias analizadas es aún limitada por tres razones. Primero, en lo que respecta al concepto de tortura; como advertimos, la Corte IDH se ha ceñido de manera literal a los textos normativos limitando su desarrollo progresivo. Sin embargo, la Corte no está atada a la letra de las convenciones si existe una fórmula que otorgue una mayor y mejor protección a los derechos de las víctimas de tortura, por ello perdió la posibilidad de adoptar la postura amplia que, en cambio, sí fue abrazada por otros tribunales internacionales. Segundo, la Corte IDH abordó la violencia de género preferentemente a través del análisis de la violencia sexual. Sin embargo, la violencia de género se manifiesta de diversas maneras, a veces como violencia física, en ocasiones como violencia simbólica bajo el ropaje de discursos e imágenes representativas de relaciones asimétricas de poder entre los sexos y de desigualdades estructurales, también a través de la discriminación laboral, la negociación de salarios o la diferenciación de remuneraciones por igual tarea, el uso sexista e invisibilizador del lenguaje, los códigos de vestimenta y estética que impone cada cultura, la transmisión de mandatos y roles, el aislamiento, la manipulación con los hijos, la dependencia económica, entre otras circunstancias. Tercero, omitió aplicar una perspectiva de género, por ejemplo, en los casos Tiu Tojin, Perozo y Ríos. Para la Corte IDH, no todos los casos en los que las víctimas de violaciones a los derechos humanos son mujeres configuran cuestiones de género. En Tiu Tojin c. Guatemala ${ }^{103}$ se trata sobre la desaparición

103 Corte IDH, Tiu Tojin c. Guatemala (2008). 
forzada de María Tiu Tojin y su hija Josefa, ocurrida el 29 de agosto de 1990, en manos de efectivos del Ejército, en el contexto de un patrón de violaciones masivas y sistemáticas de los DD.HH. en perjuicio de ciertos grupos mayas (a los que pertenecían las víctimas) durante el conflicto armado interno de Guatemala. La Corte determina la falta de acceso a la justicia de la población maya, no obstante no hace referencia a las dificultades mayores que pueden sufrir las mujeres indigenas en particular (a pesar de que se citan en la sentencia testimonios de mujeres indígenas sobre las dificultades que tuvieron para acceder a la justicia). ${ }^{104} \mathrm{~A}$ su vez, en Ríos $y$ otros c. Venezuela, ${ }^{105}$ funcionarios públicos y particulares cometieron actos que constituyeron restricciones a la labor de buscar, recibir y difundir información de 20 personas (entre ellas cinco mujeres), todas ellas periodistas o trabajadores de la comunicación social vinculados a la emisora de televisión Compañía Anónima Radio Caracas Televisión. La Corte IDH consideró necesario aclarar que no toda violación de un derecho humano cometida en perjuicio de una mujer conlleva necesariamente una violación de las disposiciones de la Convención de Belém do Pará. Admite que aunque las periodistas mujeres fueron agredidas en los hechos de este caso, en todas las situaciones lo fueron junto a sus compañeros varones. Advierte entonces que los representantes no demostraron en qué sentido las agresiones fueron "especialmente dirigidas contra las mujeres" ni explicaron las razones por las cuales las mujeres se convirtieron en un mayor blanco de ataque "por su condición de mujer". ${ }^{106}$ Tampoco habrían fundamentado sus alegatos en la existencia de actos que, bajo los artículos 1 y 2 de la Convención de Belém do Pará, puedan ser conceptualizados como "violencia contra la mujer" ni cuáles habrían sido "las medidas apropiadas" que, bajo el artículo 7.b) de aquélla, el Estado habría dejado de adoptar en este caso "para modificar o abolir leyes y reglamentos vigentes, o para modificar prácticas jurídicas o consuetudinarias que respalden la persistencia o la tolerancia de la violencia contra la mujer”. En definitiva, la Corte considera que no corresponde analizar los hechos del presente caso bajo las referidas disposiciones de la Convención de Belém do Pará. Por último, en el caso Perozo y otros $c$. Venezuela, agentes estatales y particulares cometieron, entre octubre de 2001 y agosto de 2005, diversos actos de hostigamiento y agresiones físicas y verbales, así como obstaculizaciones a las labores periodísticas en perjuicio de 44 personas vinculadas al canal de televisión Globovisión, entre periodistas,

104 Corte IDH, Tiu Tojin c. Guatemala, párrs. 92 y 97.

105 Corte IDH, Ríos y otros c. Venezuela (2009).

106 Corte IDH, Ríos y otros c. Venezuela (2009), párr. 280. 
personal técnico asociado, empleados, directivos y accionistas. La Corte decidió que la Convención de Belém do Pará no era aplicable al presente caso por las mismas razones manifestadas en el caso "Ríos $c$. Venezuela". 107

En suma, las producciones de la Corte IDH hablan de la aplicación de una perspectiva de género; sin embargo, ésta aún presenta déficits en el alcance de lo que se considera violencia contra las mujeres; así como en la calificación de la tortura cuando es perpetrada por particulares, como así también en la aplicación de una perspectiva de género en casos en los que las víctimas son mujeres. En cuanto a la calificación de la violencia contra las mujeres, en las producciones del SIDH aparece acertadamente caracterizada como discriminación e incluso desde una perspectiva de igualdad material y/o fáctica. Sin embargo, esta caracterización no siempre se traduce en medidas reparatorias que desarmen la desigualdad estructural en perjuicio de las mujeres. Este punto surge cuando se analiza con detenimiento las medidas reparatorias ordenadas en los casos de violencia contra las mujeres. Veamos.

\section{DeterminaCión de las aCCiONeS PARA EVITAR la Violencia DE GÉNERO Y LAS REPARACIONES PARA LAS VIOLACIONES \\ DE LOS DERECHOS HUMANOS DE LAS MUJERES}

La Corte IDH está facultada para establecer medidas reparatorias una vez que ha determinado la violación de una o más obligaciones enumeradas en la $\mathrm{CADH}$ y para supervisar el cumplimiento de las sentencias por parte de los Estados. Si se analiza la jurisprudencia de la Corte IDH en materia de reparaciones se advertirá una tendencia progresiva a incorporar la perspectiva de género en el diseño de las diversas medidas. Precisamente, es en la sentencia del caso Campo Algodonero donde el Tribunal indicó expresamente por primera vez que las reparaciones debían orientarse por una perspectiva de género en tanto la violencia causa un impacto diferenciado en varones y mujeres. ${ }^{108}$ Esta medida específica replica el objeto y fin de la Convención de Belém do Pará, que en el artículo 7.b establece que los Estados ratificantes deben "actuar con la debida diligencia para prevenir, investigar y sancionar la violencia contra la mujer".

107 Corte IDH, Perozo y otros c. Venezuela (2009), párr. 296.

108 Corte IDH, González y otras (“Campo Algodonero”) c. México (2009), párr. 251. V. Rubio-MaRín (2007), pp. 13-26. 
En los casos que vimos, dada la envergadura de las violaciones alegadas (violencia sexual extrema, desapariciones forzadas, masacres y crímenes de derecho internacional humanitario), la restitución al estado de cosas anterior es materialmente imposible, insuficiente o inadecuada. Por ello proceden las restantes medidas reparatorias, como la indemnización, la rehabilitación, la satisfacción y la no repetición. En esta dinámica, la Corte, por un lado, evalúa los montos indemnizatorios teniendo en consideración las formas de violencia específicas que sufren las mujeres y los contextos en los que ello tiene lugar; por el otro, elabora medidas de tipo preventivas cuya eficacia está orientada a desmantelar las distintas situaciones de desigualdad estructural ${ }^{109}$ que subyacen y posibilitan la violencia de género.

Las circunstancias de las víctimas en relación con su modo o posibilidad de ejercer sus derechos condicionan el monto indemnizatorio. En el caso Penal Miguel Castro Castro, la Corte sostuvo que la violencia sexual y los actos de tortura que sufrieron las internas, algunas de ellas embarazadas, durante el ataque al penal, constituyó un elemento a valorar al momento de determinar la compensación. En este mismo sentido, en Fernández Ortega y en Rosendo Cantú, la Corte consideró la situación de especial vulnerabilidad de la víctima, dada por su doble condición de indígena y niña.

La suma que se entrega en concepto de indemnización difícilmente reemplace el sufrimiento de las víctimas y de sus familiares. Por este motivo el daño moral se repara de variadas maneras que combinan la compensación pecuniaria y las medidas de satisfacción.

Las medidas de rehabilitación consisten en el tratamiento médico y psicológico que debe proporcionar el Estado a las víctimas para atender sus padecimientos físicos y psíquicos. En los casos de violencia sexual el tratamiento debe ser brindado por profesionales especializadas/os y adecuarse a las especificidades de género y/o etnicidad si corresponde. ${ }^{110}$ Un presupuesto de la efectividad de la rehabilitación es que incluya la provisión gratuita de medicamentos, transporte e intérprete. En los casos específicos de mujeres indígenas, ello resulta fundamental: las víctimas suelen encontrarse en situación de suma pobreza, lo cual les impediría acceder por sí mismas a estos tratamientos onerosos; además, no abundan los profesionales

109 SABa (2007); Clérico/Aldao (2011); Young (2011).

110 Cfr. Corte IDH, Fernández Ortega c. México (2010), párr. 251. 
que manejen las lenguas maternas de las mujeres indígenas, con lo cual se dificulta la comprensión de los hechos por el/la profesional. ${ }^{111}$

\subsection{Medidas de satisfacción}

Se trata de una reparación simbólica a través de la cual el Estado reconoce a las víctimas en su condición de tales y asume públicamente su responsabilidad en la violación de los derechos humanos. La reparación no reemplaza lo que se perdió (la vida, la integridad, el proyecto de vida, los vínculos familiares, las amistades, entre otras) ni puede cubrir la integralidad de los daños sufridos por la víctima por cuanto en sí mismo es irreparable, sino que, en cambio, lo representa. Este tipo particular de medidas deben estar orientadas desde la perspectiva de la víctima de violencia de género, pues con frecuencia las circunstancias de cada una de ellas se traducen en una intersección de discriminaciones en tanto la violencia puede impactar de manera específica si se encuentran embarazadas, si sufren abuso sexual, si son indígenas o niñas, entre otras situaciones. ${ }^{112}$

Para la Corte, la sentencia es una forma de reparación per se que opera directamente sobre el sentimiento de impunidad que genera la falta de investigación de los hechos por parte del Estado. Sin duda, la determinación de las responsabilidades por parte de un tribunal internacional especializado constituye una respuesta concreta frente a la necesidad de las víctimas a ser escuchadas frente a cuadros de denegación de justicia. Además, se suele ordenar que la sentencia en la que consta la determinación de la responsabilidad estatal directa o indirecta por actos de violencia hacia la mujer debe ser publicada en el Boletín Oficial del país demandado, en diarios de amplia circulación e inclusive en las páginas web oficiales. Asimismo, se ordena que el Estado debe reconocer públicamente su responsabilidad en una ceremonia oficial a la que deben asistir autoridades estatales de alto rango y deben sufragarse los gastos necesarios para que puedan trasladarse los familiares de las víctimas, si así fuera la voluntad de aquellas. La Corte suele disponer que el acto se divulgue por radio, televisión o video y se distribuya entre las distintas instancias del gobierno y de la organización civil. ${ }^{113}$

111 Cfr. Corte IDH, Rosendo Cantú c. México (2010), párr. 252.

112 V. Nash Rojas (2009), p. 54.

113 Cfr. Corte IDH, Masacre de Las Dos Erres c. Guatemala (2009), párr. 256; González y otras (“Campo Algodonero") c. México (2009), párrs. 469 y 470. 
En Plan de Sánchez, la Corte dispuso que no bastaba con que el Estado hubiera realizado el reconocimiento de responsabilidad en una audiencia pública celebrada en el marco del proceso internacional, sino que para que el acto tuviera efectos verdaderamente reparatorios debía realizarse en la propia aldea con la participación de las víctimas sobrevivientes y de los líderes en idioma español y también en el idioma maya achí (la lengua comunitaria) y además debía difundirse a través de los medios de comunicación.

El reconocimiento social y público de la violación también tendría un efecto de atenuación sobre el dolor de las víctimas. Esto adquiere un matiz especial en los casos de violencia de género, por cuanto la determinación de las responsabilidades permite a las víctimas reelaborar su grado de interferencia con los hechos. La Corte en los últimos años ha redefinido el análisis de este tipo de casos y ha destacado los diversos modos y matices en que las mujeres son revictimizadas a través del castigo social al que deben enfrentarse ante situaciones de violencia sexual ${ }^{114} \mathrm{o}$ al ser atendidas por las autoridades sanitarias, policiales y judiciales que explícita o implícitamente las responsabilizan a ellas o a sus familiares por lo que les ha ocurrido. ${ }^{115}$

La construcción de un monumento en memoria de las personas víctimas de los hechos se ha constituido en una medida de satisfacción frecuentemente ordenada por la Corte. Por ejemplo, en respuesta a esta medida reparatoria se construyó en el cementerio de Las Cruces -que es el departamento al que pertenecía el parcelamiento de Las Dos Erres- un pozo simbólico y una cruz blanca en cuya base están grabados los nombres de las víctimas. ${ }^{116}$

De todas maneras no basta con la construcción del monumento, sino que el Estado debe garantizar su preservación en buenas condiciones para que la construcción de la memoria colectiva surta efecto también como garantía de no repetición. En este orden de cosas, la Corte dispuso que Guatemala debía destinar una partida presupuestaria determinada para el mantenimiento y mejoras en la infraestructura de la capilla en la cual las víctimas rinden tributo a las personas

114 V. "Rosendo Cantú", párr. 133.

115 V. “Campo Algodonero”, párr. 198.

116 V. Amnistía Internacional (2002), pp. 45-49. La construcción recuerda al pozo Arévalo -excavado en 1979 por un hombre de apellido homónimo que buscaba agua- que el 7 de diciembre de 1982 recibió los cuerpos vivos de 162 personas entre niñas y mujeres previamente violadas en masa, niños y hombres arrojados por los miembros del comando de kaibiles. 
que fueron ejecutadas en la Masacre Plan de Sánchez, lo que permitiría conservar la memoria de las personas asesinadas, muchas de ellas mujeres. ${ }^{117}$

En el caso Penal Miguel Castro Castro, la Comisión Interamericana había solicitado a la Corte que ordenara la construcción de diversos monumentos en honor a las víctimas. El Estado respondió que se había construido un monumento denominado "El Ojo que llora”. No obstante, la Corte expresó que ello era insuficiente, pues era imprescindible que se incorporara una inscripción que contuviera los nombres de todas las personas fallecidas con motivo del ataque al penal.

Más adelante, en "Rosendo Cantü", la Corte ordenó al Estado que proporcionara becas de estudio en instituciones públicas para cubrir los costos de la educación de Valentina Rosendo Cantú (que tenía 17 años cuando fue violada por militares) y su hija -que para aquel momento tenía meses de vida- hasta que concluyeran el nivel superior. El abandono por parte de su esposo, la condena social de la comunidad y la continua denegación de justicia llevaron a la señora a alejarse drásticamente de su tierra y de su cultura, lo que desmembró los lazos familiares y afectó gravemente la construcción de identidad de su niña. En este contexto, se afectó su proyecto de vida y la posibilidad de estudiar de ambas quedó relegada. Las becas de estudio también fueron ordenadas en favor de los cuatro hijos de Inés Fernández Ortega en el caso contra México resuelto por la Corte.

\subsection{Garantías de no repetición}

Se trata de ciertas acciones o actividades que se establecen con "efecto social" para garantizar que los hechos lesivos no se repitan. Si se pretende desmantelar el contexto de desigualdad estructural que posibilita las violaciones de derechos humanos, las medidas deben tener una vocación correctiva o incluso transformadora.

Por ejemplo, en "La masacre de Las Dos Erres", la Corte ordenó la elaboración, edición y posterior difusión de un video documental en el que participen las víctimas y sus familiares narrando los hechos del caso y se indique a cada uno de los responsables a fin de crear conciencia sobre la población para que los hechos no se repitan.

Asimismo, la Corte destaca la importancia de la implementación de programas de capacitación para funcionarios judiciales y miembros de las fuerzas de seguridad sobre derechos humanos. El temario debe incluir estrategias de investigación de patrones de violencia masiva y sistemática de derechos humanos y la tutela judi-

117 Cfr. Corte IDH, Masacre de Plan de Sánchez c. Guatemala (2004), párr. 104. 
cial efectiva para encauzar y dirigir este tipo de procesos en un plazo razonable, investigar los hechos y sus responsables, así como también garantizar el acceso a la justicia por parte de las víctimas. En "Penal Miguel Castro Castro", bajo el subtítulo de medidas educativas, se indica que el Estado, en su función de garante de la vida y la integridad de las personas que se encuentran bajo su custodia, debe capacitar adecuadamente a los miembros de fuerzas de seguridad sobre los estándares aplicables en materia de tratamiento de reclusos. Si bien es destacable la capacitación en derechos humanos, fue recién en el caso "Campo Algodonero" (2009) cuando la Corte ordenó por primera vez la incorporación de la perspectiva de género en el diseño de los cursos de capacitación como garantías de no repetición. Ocho días después el Tribunal dictó sentencia en "Masacre de Las Dos Erres" y sorpresivamente no ordenó la implementación de cursos de capacitación en materia de violencia hacia la mujer. En su voto concurrente, el juez ad hoc Ramón Cadena Rámila afirmó que en atención a los graves hechos de violencia sexual que habían sufrido las mujeres en el caso, correspondía establecer medidas específicas de reparación. Entre éstas enumeró las siguientes: la capacitación de los funcionarios de las fuerzas de seguridad y del Ministerio Público en las causas, la naturaleza y las consecuencias de la violencia de género; la implementación de medidas de protección para garantizar a las mujeres una vida libre de violencia y en especial para prevenir el abuso y la violación sexual de mujeres bajo custodia, y el castigo de los delitos contra las mujeres. Meses más tarde, en el caso "Fernández Ortega" la Corte ordenó la implementación de una capacitación regular que aborde no sólo la violencia hacia las mujeres, sino también la interacción entre género y pueblos indígenas.

\subsection{Medidas reparatorias colectivas}

La Corte interpreta que la gravedad de las violaciones a los derechos humanos en materia de violencia hacia las mujeres repercute directamente sobre la comunidad o el grupo social al que pertenecen las víctimas. Por este motivo, la Corte ha ordenado medidas de reparación con perspectiva colectiva bajo la modalidad de la satisfacción y de la garantía de no repetición, en especial en relación con los pueblos indígenas. En estos casos se advierte el impacto colectivo que genera la violencia de género sobre las comunidades respectivas. El daño se prolonga a través de sus víctimas individuales, las trasciende y, por tanto, afecta el tejido familiar y comunitario. Piénsese, por ejemplo, en el caso del pueblo guatemalteco de Plan de Sánchez, donde quedaron pocas mujeres después de la masacre perpetrada por los kaibiles. La gran mayoría de ellas habían sido violadas y asesinadas en dichas 
circunstancias. Una de las consecuencias de esta masacre -según la descripción de un testigo- fue que "los hombres sobrevivientes se unieron con mujeres de otras comunidades". ${ }^{118}$ Nieve Dupuis, perito designada en el caso, señaló que los roles familiares y la transmisión oral de la cultura maya achí, a cargo de las mujeres, quedaron desarticulados por la muerte de aquellas. ${ }^{119}$ Esta nueva realidad impactó en la comunidad en su conjunto, modificó la estructura familiar y con ello su cultura.

Aunque la Corte no dictó medidas de reparación de las violaciones sexuales, sí ordenó al Estado de Guatemala la realización de acciones concretas para preservar la memoria colectiva y la lengua de la comunidad maya achí, lo que implica en cierto modo revalorizar la función de las mujeres en aquella comunidad. ${ }^{120}$ Asimismo, la Corte dispuso que el Estado tradujera al idioma achí el texto de la Convención Americana y de la sentencia y facilitara su divulgación. Aunque no surja explícitamente, esta medida aborda la situación de la falta de acceso a la justicia por parte de las mujeres que la Comisión ha precisado reiteradamente en sus informes temáticos y a lo que la Corte ha llamado la atención en "Campo Algodonero", "Tiu Tojin", "Fernández Ortega" y "Rosendo Cantü".

El conocimiento de los derechos contribuye a dotar de herramientas de protección y de garantía a los miembros de la comunidad ante la posibilidad de que se repitan los hechos. En el marco de las reparaciones colectivas de Plan de Sánchez, la Corte ordenó que el Estado de Guatemala incluyera el estudio y la difusión de la cultura maya achí en las comunidades afectadas a través de la Academia de Lenguas Mayas de Guatemala u otra organización similar; realizara mejoras en el sistema de comunicación vial entre las comunidades, en el sistema de alcantarillado y suministro de agua potable; dotara de personal docente capacitado en enseñanza intercultural y bilingüe en los distintos niveles educativos de dichas comunidades, y estableciera un centro de salud en la aldea de Plan de Sánchez orientado a brindar atención médica y psicológica a las personas afectadas por la masacre. Sin duda, estas medidas de "repercusión pública"121 también benefician a las mujeres, en especial las que operan sobre el sistema de salud y el acceso al agua potable.

\footnotetext{
118 Testimonio de la víctima Buenaventura Manuel Jerónimo.

119 Cfr. Corte IDH, Masacre de Plan de Sánchez c. Guatemala (2004), párr. 49.12.

120 Cfr. Corte IDH, Masacre de Plan de Sánchez c. Guatemala (2004), párr. 49.19.

121 Corte IDH, Masacre de Plan de Sánchez c. Guatemala (2004), voto del Juez S. Ramírez, párr. 29.
} 
En el caso Sawhoyamaxa (2006), la Corte resaltó que las condiciones de extrema pobreza en que se encontraban los integrantes de una comunidad indígena facilitaba la aparición de casos de mortalidad materna. Posteriormente, en Xákmok Kásek (2010), la Corte ordenó al Estado que, en aras de garantizar la vida en condiciones dignas, brinde atención médica especial a las mujeres en estado de embarazo y postembarazo, lo que incluye la asistencia con personal entrenado adecuadamente para la atención de los nacimientos y la implementación de políticas de prevención de la mortalidad materna a través de controles prenatales y postparto adecuados. ${ }^{122}$

En Fernández Ortega, la Corte requirió al Estado la construcción de una escuelaalbergue para que las niñas indígenas del estado mexicano de Guerrero pudieran estudiar y, además, para que funcione como un centro comunitario donde se desarrollen actividades de difusión de los derechos humanos y de la mujer. Se trata de una medida que ataca causas concretas de desigualdad estructural que impiden a las niñas acceder a iguales oportunidades de educación. Fue necesario tener en cuenta que la escuela más cercana quedaba a tres horas de caminata y que en la ruta de comunicación se producían frecuentes ataques sexuales. Muchas madres decidían enviar a sus hijas a las casas de familias mestizas que vivían en ciudades céntricas para trabajar como empleadas domésticas en jornadas laborales diarias de doce horas de duración, a cambio de comida y alojamiento para poder estudiar.

Respecto del derecho a la salud, los Estados deben implementar programas de atención a las víctimas de violencia sexual, desarrollar protocolos específicos de atención y dotar con recursos materiales adecuados y personal capacitado a los centros de salud integrales para que estén en condiciones de atender a las mujeres de la comunidad. Ello requiere que los centros sanitarios se encuentren en las cercanías de los pueblos para que las mujeres no deban recorrer grandes distancias o trasladarse (por el costo que ello implica) y que cuenten con traductores de la lengua indígena. La concentración de los recursos institucionales en las ciudades constituye una barrera al acceso por parte de las mujeres indígenas y rurales. Por ello, en Rosendo Cantú la Corte alentó la implementación de servicios itinerantes de sensibilización y detección de la violencia hacia la mujer, como también la mejora en el acceso a los servicios de atención telefónica por parte de las mujeres de la zona donde ocurrieron los hechos. Esta medida claramente busca corregir la situación de "violencia castrense" existente en el estado de Guerrero (México),

122 Cfr. Corte IDH, Comunidad Indígena Xákmok Kásek c. Paraguay (2010), párr. 301; Comunidad Indígena Sawhoyamaxa c. Paraguay (2006), párr. 230. 
en que "la población indígena se encuentra en una situación de vulnerabilidad, reflejada en diferentes ámbitos, como la administración de justicia y los servicios de salud, particularmente, por no hablar español y no contar con intérpretes, por la falta de recursos económicos para acceder a un abogado, trasladarse a centros de salud o a los órganos judiciales y también por ser víctimas de prácticas abusivas o violatorias del debido proceso [...] situación que se agrava para las mujeres indígenas puesto que la denuncia de ciertos hechos se ha convertido para ellas en un reto que requiere enfrentar muchas barreras, incluso el rechazo por parte de su comunidad y otras 'prácticas dañinas tradicionales". ${ }^{123}$

\subsection{La obligación de investigar}

La obligación de investigar es preexistente al dictado de la sentencia y persiste luego si el Estado no la ha garantizado: por un lado, de manera genérica, el Estado tiene la obligación de investigar los hechos violatorios de normas fundamentales que ocurren en su territorio en virtud del artículo 1.1 de la Convención. Si no lo hace, surge su responsabilidad internacional y lo que no hizo antes deberá hacerlo después si es condenado en sede internacional.

Aun cuando los Estados realicen investigaciones para determinar "la verdad histórica”, la Corte IDH específicamente ordena que la investigación debe realizarse en el marco de un proceso judicial interno que determine los hechos, las víctimas, los responsables y las sanciones correspondientes. Esta investigación no debe ser realizada como un mero trámite, sino que tiene que ser efectiva, aun cuando la obligación de investigar es de medios y no de resultados. Debe garantizar un verdadero acceso a la justicia por parte de las víctimas, dentro de un plazo razonable, que abarque el esclarecimiento de los hechos, la investigación, persecución, la captura, el enjuiciamiento y la eventual sanción de todos los presuntos responsables. ${ }^{124}$

123 Cfr. Corte IDH, Rosendo Cantú c. México, 2010, párr. 70; Fernández Ortega c. México (2010), párr. 78. Sin embargo, la Corte determinó en el mismo caso que eran improcedentes tres medidas reparatorias solicitadas por la $\mathrm{CIDH}$ y los representantes de las víctimas en virtud de que no las fundamentaron de manera sustancial. En realidad, tal como fue analizado por la jueza Rhadys Abreu Blondet en Rosendo Cantú, la falta de pruebas no era óbice para que la Corte ordenara aquellas reparaciones en virtud del principio iura novit curia. Además, de acuerdo a la pauta interpretativa que surge del artículo 29. a de la Convención Americana, la Corte podría y debería haberlas declarado procedentes porque dotan de un contenido mayor a los derechos y persiguen la corrección de una situación de desigualdad estructural manifiesta en la región de Guerrero.

124 Corte IDH, Masacre de Las Dos Erres c. Guatemala (2009), párr. 231; Rosendo Cantú c. México (2010), párr. 211. 
Campo Algodonero es el primer caso en el que la Corte señaló que la investigación debe adoptar una perspectiva de género: debe ser realizada por funcionarias/ os altamente capacitadas/os en casos de discriminación y violencia por razón de género y debe abarcar el desarrollo de líneas de investigación específicas respecto a la violencia sexual, la utilización de protocolos y manuales específicos y de la consideración del impacto diferenciado que pudieron haber sufrido las mujeres y las niñas víctimas en su integridad. ${ }^{125}$ En los casos Fernández Ortega, Rosendo Cantú y Tiu Tojin, la Corte también ordenó la provisión de intérpretes para que las víctimas pudieran participar en las diligencias de los casos. ${ }^{126}$

En la Masacre de Las Dos Erres, la Corte además hace referencia expresa a la Recomendación No 19 de la CEDAW, que establece que deben considerarse procedimientos eficaces de reparación cuando se trata de violencia hacia la mujer en el marco de conflictos armados, ${ }^{127}$ como clasificó la propia Corte a los hechos. ${ }^{128}$

La remoción de los obstáculos legales y estructurales constituye la clave para que sea eficaz la investigación sobre hechos de violencia contra las mujeres y para que éstos no se repitan. En este contexto, el acceso a la justicia -no sólo de iure, sino de facto- por parte de las mujeres deviene fundamental. Las actitudes discriminatorias de las autoridades policiales y judiciales se traducen en una demora innecesaria en los procedimientos de actuación y de investigación que requieren inmediatez, en la inactividad de la actividad procesal, en la negligencia en la recolección de pruebas y en la falta de contextualización de la violencia motivada en el género. La combinación de estos elementos provoca la reproducción de los mecanismos de violencia hacia la mujer. Por ello, en respuesta al cuadro de denegación de justicia que sufren las mujeres, la Corte ordena a los Estados que investiguen, sancionen y remuevan de sus cargos a los funcionarios que hayan cometido irregularidades en los procesos internos de investigación ${ }^{129}$. Si se desea erradicar el patrón sistemático de violencia hacia la mujer, se requiere que los Estados se involucren fuertemente en una modificación sustancial de los sistemas

125 Cfr. Corte IDH, González y otras (“Campo Algodonero”) c. México (2009), párr. 455.ii; Masacre de Las Dos Erres c. Guatemala, 2009, párr. 233.b.

126 Cfr. Corte IDH, Rosendo Cantú c. México (2010), párr. 213.

127 Cfr. Comité para la Eliminación de la Discriminación contra la Mujer, Recomendación General 19: La Violencia contra la Mujer (11 Período de Sesiones 1992), ONU Doc.A/47/38, párr. 16.

128 Corte IDH, Masacre de Las Dos Erres c. Guatemala (2009), Sentencia de 24 de noviembre de 2009, párr. 140.

129 Cfr. Corte IDH, Rosendo Cantú c. México (2010), párr. 214. 
de justicia y de los operadores jurídicos, como así también de los funcionarios policiales. A estos efectos, sin dudas, se dirige la capacitación en materia de género que ordenó la Corte en Campo Algodonero.

La remoción de obstáculos legales puede implicar la necesidad de modificar el ordenamiento jurídico del Estado responsable, porque los Estados no pueden alegar la existencia de disposiciones del derecho interno para incumplir lo dispuesto por la Corte. Esta medida de reparación se confunde con la obligación que surge del artículo 2 de la Convención Americana, que establece que los Estados deben adoptar las medidas legislativas o de otro carácter que fueren necesarias para hacer efectivos los derechos y libertades consagrados en el texto convencional. Por ejemplo, en Masacre de Las Dos Erres, la Corte ordenó al Estado la adopción de medidas legislativas y de todo tipo necesarias para regular la ley de amparo a los fines de adecuar la eficacia de este recurso a los estándares interamericanos en materia de protección de los derechos humanos. ${ }^{130}$

El reverso de la obligación de investigar se traduce en el "derecho a la verdad" individual y social. ${ }^{131}$ Para las víctimas, conocer la verdad de los hechos puede implicar un apaciguamiento del dolor que haya generado la experiencia traumática y que pudo haber sido incrementado por el sentimiento de impunidad que genera la desconfianza en el sistema de justicia interno.

La Corte en reiteradas ocasiones estableció que el derecho de las víctimas a conocer dónde se encuentran los restos de las personas que fallecieron en masacres como la de Plan de Sánchez y Dos Erres constituye una forma de reparación para sus familiares; asimismo, permite obtener información para reconstruir cómo ocurrieron los hechos e indicios acerca de los posibles responsables. ${ }^{132} \mathrm{El}$ conocimiento de las formas de violencia que sufren las mujeres en estas situaciones permite analizar la existencia de un patrón de violencia en razón del género y, en consecuencia, desarrollar planes de acción para contrarrestarla y repararla.

El deber de investigar analizado como obligación genérica del cuerpo de derechos (artículo 1.1 de la $\mathrm{CADH}$ ) y correlativamente como una medida reparatoria deviene altamente estratégico, por cuanto de este modo la Corte Interamericana

130 Cfr. Corte IDH, Masacre de Las Dos Erres c. Guatemala (2009), párr. 242.

131 Cfr. Corte IDH, Gelman c. Uruguay (2011), párr. 243.

132 Cfr. Corte IDH, Masacre de Las Dos Erres c. Guatemala (2009), párr. 245: "Los restos son una prueba de lo sucedido y ofrecen detalles del trato que recibió, la forma en que fue ejecutada, el modus operandi. El lugar mismo en el que los restos son encontrados puede proporcionar información valiosa sobre los perpetradores o la institución a la que pertenecían" y el sexo de las personas asesinadas, entre otros. 
puede no sólo declarar su violación, sino también supervisar su cumplimiento en la instancia de ejecución de la sentencia. Esto implica, por ejemplo, que el Estado debe entregar a la Corte informes periódicos en los que detalle los avances que ha puesto en marcha respecto de cada una de las medidas de reparación.

\section{CONSIDERACIONES INTERMEDIAS}

Respecto de las medidas de erradicación de la violencia de género, se diría que tanto para la Comisión como para la Corte IDH es prioritario el acceso a la justicia. Tal como ha sido documentado, los casos de violencia de género se caracterizan por quedar en la impunidad o por sufrir demoras injustificables en los procedimientos de actuación, investigación y sanción de los responsables. La Corte ha señalado que para erradicarla, se requieren acciones transformadoras dirigidas a desmantelar la situación de violencia estructural en razón del género, como puede ser la capacitación específica de los operadores judiciales y los integrantes de las fuerzas de seguridad en esta temática. Si bien coincidimos en que el "acceso a la justicia" es una herramienta indispensable para empezar a desarmar la violencia contra las mujeres, esta medida reparatoria general se muestra, a las claras, estructuralmente insuficiente. ${ }^{133} \mathrm{La}$ Comisión nos habla de la existencia de un estrecho vínculo entre la violencia de género y la discriminación. Esta relación exige respuestas múltiples e integrales capaces de conmover las prácticas culturales que discriminan a las mujeres y que constituyen un contundente medio de reproducción y naturalización de la violencia de género. Esto lleva a decir a la CIDH que la discriminación hacia las mujeres se manifiesta de diversas formas en todos los ámbitos: "Instituciones como la familia, el lenguaje, la publicidad, la educación, los medios de comunicación masiva, entre otras, canalizan un discurso y mensaje ideológico que condiciona el comportamiento de hombres y mujeres conforme a los patrones culturales establecidos que promueven las desigualdades. Además, refuerza los roles y estereotipos que actúan en detrimento de las mujeres". ${ }^{134}$ Por ello, las medidas transformadoras deberían ser pensadas para todos esos ámbitos, así es claro que el "acceso a la justicia" si bien fundamental, no es más que sólo un punto en la red de medidas integradas en las que se requiere avanzar. Además, es necesario que tanto la Corte IDH como la CIDH profundicen el proceso de transversalización de la perspectiva de género en el análisis de las peticiones, de

133 V. MAQUeda (2008).

134 CIDH, Acceso a la justicia para mujeres víctimas de violencia en Mesoamérica (2011), párr. 47. 
los casos y de los informes sobre la vigencia de los distintos derechos humanos en la región americana. Esto implica ampliar el abordaje de la violencia de género e incursionar en nuevas variables que exceden a las barreras en el acceso a la justicia y a los recursos judiciales idóneos y efectivos. Al respecto, identificamos, por lo menos, dos líneas de trabajo que requieren atención urgente por el SIDH:

a) Violencia de género en los medios masivos de comunicación, publicidad, entre otros: en lo que respecta a la difusión y recepción de datos, la CIDH afirmó en el año 2010 que resulta problemática la ausencia de mecanismos de regulación sobre la circulación masiva de información estereotipada o peyorativa respecto de grupos históricamente menos favorecidos, lo que tiene por efecto una discriminación en el ejercicio del derecho a la libertad de expresión. ${ }^{135}$ Precisamente, los medios de comunicación funcionan como actores protagónicos en la reproducción y difusión de estereotipos de género, lo que se traduce en violencia mediática. $\mathrm{LaCIDHy}$ la Corte IDH no han abordado aún este tema bajo aquella denominación como así tampoco la responsabilidad de los Estados en la generación de mecanismos de control de los medios de comunicación audio y/o visuales y publicidades de corte sexista. Por este motivo, sería positivo que el SIDH generara espacios y/o acciones de monitoreo sobre las imágenes, mensajes y pautas publicitarias que a través de los medios de comunicación promueven y/o construyen patrones socioculturales legitimantes de la desigualdad o generadores de violencia contra las mujeres, así como también identifiquen y divulguen las buenas prácticas en la materia.

b) Intensificar las líneas de trabajo que relacionan violencia de género y DESC. En los últimos informes temáticos publicados por la CIDH se advierte la estrecha relación entre la violencia de género y la falta de acceso a los derechos sociales, económicos y culturales. Así, sostiene que aunque “... la pobreza afecta a todas las personas, su impacto es diferente para las mujeres, dada su situación de discriminación social y la existencia de cargas adicionales, tales como las funciones familiares, lo cual limita sus posibilidades de acceder a los recursos económicos necesarios para su subsistencia, y la de sus familias. Asimismo, las desigualdades y limitaciones en el acceso y control de recursos económicos por parte de las mujeres contribuye a su baja participación en esferas vitales para sus derechos humanos". ${ }^{136}$ La feminización de la pobreza tiene un efecto replicador en la imposibilidad de ejercer diversos derechos fundamentales como la vida, la integridad, la autono-

135 Cfr. http://www.oas.org/es/cidh/expresion/showarticle.asp?artID=784\&lID=2.

$136 \mathrm{CIDH}, \mathrm{El}$ trabajo, la educación y los recursos de las mujeres: la ruta hacia la igualdad en la garantía de los derechos económicos, sociales y culturales (2011), párr. 25. 
mía, el acceso a la salud, la educación y el acceso a la vivienda, entre otros. Del mismo modo la CIDH llama la atención sobre las dificultades específicas, por las que atraviesan las mujeres cuando son víctimas de discriminación interseccional.

Por fin, si -como se desprende de los diversos documentos de la CIDH- es que en la región existen patrones de cultura dominante que implican asignación de roles sociales, lo que a su vez lleva consigo una distribución desigualitaria de poder y relacionan a las mujeres con un lugar de subordinación, ${ }^{137}$ no cabe duda de que al SIDH le queda mucho camino por andar en pos de la erradicación de la violencia contra las mujeres.

\section{Consideraciones FinAles}

Por un lado, se destaca dentro del SIDH el papel activo de la CIDH -a través de los informes temáticos, por países y de fondo- en la incorporación de la perspectiva de género en el trabajo del SIDH desde 1994, al que luego se le sumó expresamente la Corte IDH con el caso "Penal Castro Castro c. Perú" (2006). Por el otro lado, se identifican las insuficiencias que aún presentan las producciones de la Corte IDH referidas al carácter restrictivo con que se califica a la violencia de género como tortura; la centralidad que le otorga a: a) la violencia sexual opacando otros aspectos de la violencia contra las mujeres; y b) el acceso a la justicia como medida reparatoria descuidando otras líneas de acciones de carácter transformador para erradicar la violencia contra las mujeres en la región.

\section{BIBLIOGRAFÍA CITADA}

Abi-Mershed, Elizabeth A. (2008): "Due Diligence and the Fight Against GenderBased Violence in the Inter-American System", en Benninger-Budel, Carin (ed.), Due Diligence and Its Application to Protect Women from Violence (Leiden, Martinus Nijhoff Publishers), pp. 127-138.

ABRAmovich, Víctor (2010): "Responsabilidad estatal por violencia de género: comentarios sobre el caso 'Campo Algodonero' de la Corte Interamericana de Derechos Humanos", Anuario de Derechos Humanos, Centro de Derechos Humanos de la Facultad de Derecho, Universidad de Chile, pp. 167-182. AmNistía InTERnaCional (2002): El legado mortal de Guatemala. El pasado impune $y$ las nuevas violaciones de derechos humanos (Madrid, EDAI).

137 CIDH, Acceso a la justicia para mujeres víctimas de violencia en Mesoamérica (2011), párr. 47. 
CARDOSO, Evorah (2012): Litígio estratégico e sistema interamericano de direitos humanos (Belo Horizonte, Fórum).

(2011): "Ciclo de vida do litígio estratégico no Sistema Interamericano de Direitos Humanos: dificuldades e oportunidades para atores não estatais", en Revista Electrónica del Instituto de Investigaciones "Ambrosio L. Gioja", Año V, Núm. Especial, pp. 363-378.

CEJIL (2007): Guia para defensores y defensores de Derechos Humanos, Buenos Aires.

Charlesworth, Hilary (2005): "Not Waving but Drowning: Gender Mainstreaming and Human Rights in the United Nations", en Harvard Human Rights Journal, vol. 18, Harvard Law School, Cambridge, Massachusetts, pp. 1-18.

Chinkin, Christine (2012): "Acceso a la justicia, género y derechos humanos", en Defensoría General de la Nación, Violencia de género: estrategias de litigio para la defensa de los derechos de las mujeres, Buenos Aires, pp. 15-53.

Clérico, Laura y AldaO, Martín (2011): "La Igualdad como Redistribución y como Reconocimiento: Derechos de los Pueblos Indígenas y Corte Interamericana de Derechos Humanos", en Estudios Constitucionales, vol. 9, n. 1.

Consejo Nacional de Mujeres (2011): "Publicidad televisiva: la violencia detrás de los estereotipos", disponible en http://www.cnm.gov.ar

Copelon, Rhonda (2000): "Gender Crimes as War Crimes: Integrating Crimes against Women into International Criminal Law”, en McGill Law Journal, vol. 49 , pp. 217-240.

Crenshaw, Kimberlé (1999): "Intersectionality, Identity Politics, and Violence Against Women of Color”, en Stanford Law Review, Núm. 43, pp. 1241-1299.

ELA (2012): "Más allá de la denuncia. Los desafíos del acceso a la justicia”, disponible en http://www.ela.org.ar

GHERARDI, Natalia (2012): "La violencia contra las mujeres en la región”, en Alméras, Diane; Calderón Magaña, Coral (coord.), Si no se cuenta, no cuenta. Información sobre la violencia contra las mujeres, Chile, CEPAL, pp. 13-176. Giberti, Eva y Fernández, A. (1989): La mujer y la violencia invisible (Buenos Aires, Sudamericana).

Gutiérrez Castañeda, Griselda (2008): "Violencia sexista. De la violencia simbólica a la violencia radical”, en Debate Feminista, Año 19, Vol. 37, pp. 34-48.

Hunter, Rosemary (2010): “An Account of feminist judging”, en Hunter, Rosemary; McGlynn, Clare y Rackley, Erika (eds.), Feminist judgements. From Theory to Practice (Oxford, Hart), pp. 30-43. 
Laudano, Claudia N. (2010): "Visibilidad mediática de la violencia hacia las mujeres en Argentina (1983-2009)", en Revista Derecho y Ciencias Sociales, No 3, pp. 88-110.

(2006): "Género: te habíamos amado tanto", en Cuadernos de la Facultad de Humanidades y Ciencias Sociales, No 31, pp. 147-160.

Lemaitre, Julieta (2008) "Violencia", en Motta, Cristina y Sáez, Macarena (eds.): La mirada de los jueces. Género en la jurisprudencia latinoamericana, Bogotá, Colombia.

MaCKINNON, Catherine (1989): Hacia una teoría feminista del Estado, Ediciones Cátedra-Universidad de Valencia-Instituto de la Mujer.

MaffíA, Diana (2012): “Hacia un lenguaje inclusivo, ¿es posible?”, Jornadas de actualización profesional sobre traducción, análisis del discurso, género y lenguaje inclusivo (Buenos Aires, Universidad de Belgrano).

MAQUeDA, María Luisa (2008): “¿Es la justicia penal una solución a la violencia contra las mujeres? Algunas respuestas desde el feminismo crítico”, en Género, Violencia y Derecho, Patricia Laurenzo, María Luisa Maqueda y Ana Rubio (Coordinadoras), Tirant lo Blanch alternativa, Valencia.

Marshall, Jill (2005): "Torture Committed by Non-State Actors: The Developing Jurisprudence from the Ad Hoc Tribunals", en Non-State Actors and International Law, vol. 5, Leiden, Martinus Nijhoff Publishers, pp. 171-182.

Mc Henry, James R. (2002): “The Prosecution of Rape under International Law: Justice that is Long Overdue", en Vanderbilt Journal of Transnational Law, vol. 35, Vanderbilt University Law School, Nashville, pp. 1269-1311.

Medina Quiroga, Cecilia (2003): "Human Rights of Women: Where are we now in the Americas?", en Manganas, A. (ed.), Essays in Honour of Alice Yotopoulos-Marangopoulos, Vol. B, Atenas, Nomiki Bibliothiki Group, Panteion University, pp. 907-930.

Muñoz Cabrera, Patricia (2011): "Violencias Interseccionales". Debates Feministas y Marcos Teóricos en el tema de Pobreza y Violencia contra las Mujeres en Latinoamérica, CAWN, disponible en www.cawn.org

Nash Rojas, Claudio (2009): Las reparaciones ante la Corte Interamericana de Derechos Humanos (1988-2007), Santiago, Centro de Derechos HumanosUniversidad de Chile.

RuBio-Marín, Ruth (2007): "Mujer y reparación: apuntes para la reflexión”, en Asociación Pro Derechos Humanos, Para no olvidarlas más. Mujeres y reparaciones en el Perú, Perú, pp. 13-25. 
SABA, Roberto (2007): “(Des)Igualdad estructural”, en Alegre, Marcelo y Gargarella, Roberto (comp.), El derecho a la igualdad. Aportes para un constitucionalismo igualitario, Buenos Aires, LexisNexis.

SAlvioli, Fabián (1997): "Derechos, acceso y rol de las víctimas en el sistema interamericano de protección a los derechos humanos", en El futuro del sistema interamericano de protección de los derechos humanos (San José de Costa Rica, Instituto Interamericano de Derechos Humanos), pp. 293-342.

Shelton, Dinah (2002): "Righting wrongs: Reparations in the articles of States responsibility", American Journal of International Law, Vol. 96, pp. 833-856.

Sierra Camargo, Ximena (2012): Impunidad y Estructura Patriarcal en los Delitos de Violencia Sexual contra Niñas y Adolescentes. La impunidad en los crímenes de violencia sexual perpetrados por grupos paramilitares contra niñas y adolescentes en el conflicto armado colombiano, como consecuencia de la presencia de una estructura patriarcal en los procesos de Justicia y Paz, Buenos Aires, tesis de maestría, Universidad Nacional de la Plata.

Tramontana, Enzamaría (2011): "Hacia la consolidación de la perspectiva de género en el Sistema Interamericano: avances y desafíos a la luz de la reciente jurisprudencia de la Corte de San José”, en Revista IIDH, Vol. 53, pp. 141-181. YounG, Iris (2011): Responsability for justice, (Nueva York, Oxford University Press).

\section{JURISPRUDENCIA}

\section{Corte Interamericana de Derechos Humanos}

Artavia Murillo y otros ("Fertilización in vitro") c. Costa Rica (2012), Sentencia de 28 de noviembre de 2012.

Masacres de Río Negro c. Guatemala (2012), Sentencia de 4 de septiembre de 2012.

Fornerón e Hija c. Argentina (2012), Sentencia de 27 de abril de 2012.

Atala Riffo e hijas c. Chile (2012), Sentencia de 24 de febrero de 2012.

Gelman c. Uruguay (2011), Sentencia de 24 de febrero de 2011.

Rosendo Cantú y otra c. México (2010), Sentencia de 31 de agosto de 2010.

Fernández Ortega c. México (2010), Sentencia de 30 de agosto de 2010.

Comunidad Indígena Xákmok Kásek c. Paraguay (2010), Sentencia de 24 de agosto de 2010.

Masacre de Las Dos Erres c. Guatemala (2009), Sentencia de 24 de noviembre de 2009. 
González y otras (“Campo Algodonero”) c. México (2009), Sentencia de 16 de noviembre de 2009.

Dacosta Cadogan c. Barbados (2009), Sentencia de 24 de septiembre de 2009.

Garibaldi c. Brasil (2009), Sentencia de 23 de septiembre de 2009.

Anzualdo Castro c. Perú (2009), Sentencia de 22 de septiembre de 2009.

Reverón Trujillo c. Venezuela (2009), Sentencia de 30 de junio de 2009.

Blanca Kawas Fernández c. Honduras (2009), Sentencia de 3 de abril de 2009.

Perozo y otros c. Venezuela (2009), Sentencia de 28 de enero de 2009.

Ríos y otros c. Venezuela (2009), Sentencia de 28 de enero de 2009.

Tiu Tojin c. Guatemala (2008), Sentencia de 26 de septiembre de 2008.

Escué Zapata c. Colombia (2007), Sentencia de 4 de julio de 2007.

Penal Miguel Castro Castro c. Perú (2006), Sentencia de 25 de noviembre de 2006.

Masacres de Ituango c. Colombia (2006), Sentencia de 1 de julio de 2006.

Comunidad Indígena Sawhoyamaxa c. Paraguay (2006), Sentencia de 29 de marzo de 2006.

Masacre de Mapiripán c. Colombia (2005), Sentencia de 15 de septiembre de 2005.

Niñas Yean y Bosico c. República Dominicana (2005), Sentencia de 8 de septiembre de 2005.

Las hermanas Serrano Cruz c. El Salvador (2005), Sentencia de 1 de marzo de 2005.

Carpio Nicolle c. Guatemala (2004), Sentencia de 22 de noviembre de 2004.

Masacre de Plan de Sánchez c. Guatemala (2004), Sentencia de 29 de abril de 2004.

Maritza Urrutia c. Guatemala (2003), Sentencia de 27 de noviembre de 2003.

Bulacio c. Argentina (2003), Sentencia de 18 de septiembre de 2003.

Loayza Tamayo c. Perú (1997), Sentencia de 17 de septiembre de 1997.

Caballero Delgado y Santana c. Colombia (1995), Sentencia de 8 de diciembre de 1995.

Aloebotoe y otros c. Suriname (1993), Sentencia de 10 de septiembre de 1993.

Cayara c. Perú (1993), Sentencia de 3 de febrero de 1993.

Velásquez Rodríguez c. Honduras (1989), Sentencia de 21 de julio de 1989.

Velásquez Rodríguez c. Honduras (1988), Sentencia de 29 de julio de 1988.

\section{Del Tribunal Europeo de Derechos Humanos}

Angelova e Iliev c. Bulgaria (2007), Sentencia de 26 de julio de 2007. 


\section{DECISIONES}

\section{Opiniones Consultivas de la Corte Interamericana de Derechos Humanos}

Condición jurídica y derecho de los migrantes indocumentados, Opinión Consultiva OC-18/03 de 17 de septiembre de 2003. Serie A, No 18.

Condición Jurídica y Derechos del Niño, Opinión Consultiva OC 17/02 de 28 de agosto de 2002. Serie A, No 17.

Interpretación de la Declaración Americana de los Derechos y Deberes del Hombre en el Marco del Artículo 64 de la Convención Americana sobre Derechos Humanos. Opinión Consultiva OC-10/89 del 14 de julio de 1989. Serie A, No 10.

Propuesta de modificación a la Constitución Política de Costa Rica relacionada con la naturalización. Opinión Consultiva OC-4/84 del 19 de enero de 1984. Serie A, Serie 4.

\section{Medidas cautelares de la Comisión Interamericana de Derechos Humanos}

Tránsito Jurado, María Eugenia González e integrantes de la Corporación Sisma Mujer (Colombia), MC 99/10, 8 de abril de 2010.

14 Mujeres en situación de desplazamiento (Colombia), MC 1/10, 25 de marzo de 2010.

Claudia Julieta Duque Orrego y María Alejandra Gómez Duque (Colombia), MC 339/09, 23 de noviembre de 2009.

Miembros de Liga de Mujeres Desplazadas y la Liga Joven de la LMD (Colombia), MC 319/09, 18 de noviembre de 2009.

\section{Informes temáticos de la Comisión Interamericana de Derechos Humanos}

Acceso a la justicia para mujeres víctimas de violencia sexual: la educación y la salud, OEA/Ser.L/V/II. Doc. 65, 28 de diciembre de 2011.

Acceso a la justicia para mujeres víctimas de violencia en Mesoamérica, OEA/ Ser.L/V/II. Doc. 63, 9 de diciembre de 2011.

La situación de las personas afrodescendientes en las Américas, OEA/Ser.L/V/II. Doc. 62, 5 de diciembre de 2011.

Estándares jurídicos vinculados a la igualdad de género y a los derechos de las mujeres en el sistema interamericano: desarrollo y aplicación, OEA/Ser.L/V/ II.143 Doc. 60, 3 de noviembre de 2011. 
El trabajo, la educación y los recursos de las mujeres: la ruta hacia la igualdad en la garantía de los derechos económicos, sociales y culturales, OEA/Ser.L/V/ II.143 Doc. 59, 3 de noviembre de 2011.

Acceso a Servicios de Salud Materna desde una Perspectiva de Derechos Humanos, OEA/Ser.L/V/II. Doc. 69, 7 de junio de 2010.

Informe sobre Seguridad Ciudadana y Derechos Humanos, OEA/Ser.L/V.II. Doc. 57, 31 de diciembre de 2009.

Acceso a la Justicia para las Mujeres Víctimas de Violencia en las Américas, OEA/ Ser.L/V/II. Doc. 68, 20 de enero de 2007.

\section{Informes por pais de la Comisión Interamericana de Derechos Humanos}

El derecho de las mujeres a una vida libre de violencia y discriminación en Haití, OEA/Ser.L/V/II. Doc. 64, 10 de marzo de 2009.

Las mujeres frente a la violencia y la discriminación derivadas del conflicto armado interno en Colombia, OEA/Ser.L/V/II. Doc. 67, 18 de octubre de 2006.

\section{Demanda ante la Corte IDH}

CIDH, Claudia Ivette González, Esmeralda Herrera Monreal y Laura Berenice Ramos Monárrez (Casos 12.496, 12.497 y 12.498) c. Estados Unidos Mexicanos (2007), 4 de noviembre de 2007.

CIDH, Valentina Rosendo Cantú y otra c. Estados Unidos Mexicanos (2009), Caso 12.579, 2 de agosto de 2009.

\section{Informes de fondo de la Comisión Interamericana de Derechos Humanos}

Informe 170/11, Caso 12.578, María Isabel Véliz Franco y otros (Guatemala) (2011), 3 de noviembre de 2011.

Informe 80/11, Caso 12.626, Jessica Lenahan (Gonzales) y otros (Estados Unidos) (2011), 21 de julio de 2011.

Informe No 28/07, Casos 12.496-12.498, Claudia Ivette González y otros (México) (2007), 9 de marzo de 2007.

Informe No 54/01, Caso 12.051, Maria da Penha Fernandes (Brasil) (2001), 16 de abril de 2001.

Informe No 53/01, Caso 11.565, Ana, Beatriz y Cecilia González Pérez (México) (2001), 2 de abril de 2001. 
Informe 4/01, Caso 11.625, María Eugenia Morales de Sierra (Guatemala) (2001), 19 de enero de 2001.

Informe No 5/96, Caso 10.970 (1996), Raquel Martín de Mejía (Perú), del $1^{\circ}$ de marzo de 1996.

Informe 31/93, Caso 10.526, Dianna Ortiz (Guatemala) (1996), 16 de octubre de 1996.

Resolución 3/87, Caso 9.647, James Terry Roach y Jay Pinkerton (Estados Unidos) (1987), 22 de septiembre de 1987, Informe Anual de la CIDH 1986-87. 